\title{
CONTRATACIÓN PÚBLICA Y COLUSIóN. DERECHO DE COMPETENCIA FRENTE AL DERECHO ADMINISTRATIVO*
}

\section{AN OVERVIEW ON BID-RIGGING. COMPETITION LAW V. ADMINISTRATIVE LAW}

\author{
Johannes San Miguel-Giralt ${ }^{* *}$ \\ Fecha de recepción: 23 de mayo de 2016 \\ Fecha de aceptación: 28 de febrero de 2017 \\ Disponible en linea: 30 de noviembre de 2017
}

\section{Para citar este artículo/To cite this article}

San Miguel-Giralt, Johannes, Contratación pública y colusión. Derecho de competencia frente al derecho administrativo, 135 Vniversitas, 377-420 (2017). https://doi.org/10.11144/Javeriana.vj135.cpcd

doi:10.11144/Javeriana.vj135.cpcd

* El presente artículo corresponde a la categoría ensayo académico y se inscribe en el programa de candidatura para Fondos Concursables de Investigación 2017, Universidad de Guayaquil.

** Docente titular, Universidad de Guayaquil, Ecuador. ORCID: 0000-0003-0803-1402. Doctor en ciencias jurídicas, Universidad de La Habana, 2011. Contacto: Johannes.sanm@ug.edu.ec 


\section{RESUMEN}

El presente artículo tiene por objeto la revisión y descripción del panorama doctrinal, legislativo, precedentual y casuístico de una de las modalidades de prácticas anticompetitivas: la colusión en compras públicas, y su más importante tendencia actual: la participación accionarial horizontal. De igual forma, se concluye el carácter atípico y casi embrionario del derecho de competencia en América Latina y cómo ello repercute en la represión a las prácticas anticompetitivas en la contratación pública.

Palabras clave: Colusión; derecho de competencia; contratación pública 


\section{ABSTRACT}

This paper aims to describe the theoretical, statutory, precedentual and case law on one of the forms to perform anticompetitive practices, which is bid-rigging, and its most important current trend: horizontal shareholding. Likewise, this paper states the atypical and almost embryonary stage of competition law in Latin America, and how it impacts repression to anticompetitive practices in public procurement.

Keywords: Bid-rigging; antitrust law; competition law; public procurement

\section{SUMARIO}

I. El Problema de la COLUSIÓN EN COMPRAS PÚBliCAS.- II. ACUERdos ANTICOMPETITIVos.- A. Acuerdos anticompetitivos horizontales y verticales.- B. El reciente fenómeno de la participación accionaria horizontal, horizontal shareholding.- C. Acuerdos anticompetitivos de carácter expreso, tácito o presunto.- III. Compras Públicas y SUS modalidades.- IV. Definición DE COLUSIÓN EN COMPRAS PÚBLICAS Y SUS MODALIDADES. V. EVIDENCIA INDICIARIA Y CONDICIONES DE MERCADO FAVORABLES A LA COLUSIÓN. VI. RECONOCIMIENTO NORMATIVO Y CASUÍSTICA.- CONCLUSIONES.- BibLIOGRAFÍA. 


\section{I. el PROBlema de la Colusión EN COMPRAS PÚBLICAS}

La colusión constituye la principal forma de corrupción en las compras públicas y el efecto negativo de este fenómeno está determinado por la enorme importancia relativa de estas últimas en la economía mundial, cuyo valor anual global es aproximadamente de 2 billones (millones de millones) de dólares; y en el caso de América Latina y el Caribe, las compras públicas alcanzan una cuota del 10 al 15\% del PIB regional ${ }^{1}$. Otro de los efectos negativos de la colusión contra el sector público son los costos directos que ascienden al 20-25\% del valor del contrato público, y en determinadas circunstancias se eleva hasta el $40-50 \%{ }^{2}$.

El caso de las economías en transición resulta muy interesante, porque es un excelente laboratorio de medición de la recepción social de nuevas normas relativas a la regulación del proceso de contratación pública.

En este sentido, China ha protagonizado un movimiento legislativo de represión de la colusión en compras públicas íntimamente asociado al enfrentamiento a la corrupción, dada cuenta de que la práctica anticompetitiva más común es la colusión vertical, es decir, con la participación de las propias autoridades involucradas en la convocatoria ${ }^{3}$. Otra de las cuestiones en que el caso chino demuestra ser todo un desafío - sin excluir para nada otros países - es la relación entre el poder central y las estructuras de poder territorial. La tendencia global se encamina hacia la devolución de poderes y a erigir el ámbito local como un espacio de poder autónomo desde sí, tal como lo enuncia el principio de subsidiariedad. Este protagonismo local supone un importante reto relativo a la construcción

1 Otros autores ubican su participación entre 15 y 20\%. Stefan E. WeishaAr, Cartels, Competition and Public Procurement. Law and Economics Approaches to Bid Rigging, 32-38 (Edward Elgar Publishing, Cheltenham, 2013).

2 En todos los casos, consultar: Natalia Volosin, Datos abiertos, corrupción y compras públicas, 26-35 (Iniciativa Latinoamericana por los Datos Abiertos, ILDA, OpenData, Working Paper, 2015). Disponible en: http://idatosabiertos.org/wp-content/uploads/2015/10/5.-Corrupcion-y-compraspublicas-Volosin1.pdf

3 Stefan E. Weishaar, Cartels, Competition and Public Procurement. Law and Economics Approaches to Bid Rigging, 4 (Edward Elgar Publishing, Cheltenham, 2013). 
de institucionalidad y normas para evitar y reprimir la colusión en compras públicas ${ }^{4}$.

En el caso latinoamericano, el fenómeno objeto de análisis se agrava como resultado de los caracteres que definen las economías en esta región del mundo: tamaño relativamente reducido de los mercados con escasos competidores, lo cual impide el desenvolvimiento de la concurrencia y perpetúa a escasas empresas con grandes márgenes de utilidad, agentes económicos con bajo nivel de eficiencia y productividad como resultado de una escasa competitividad sistémica o alto grado de protección política a tales empresas, escaso componente tecnológico en la producción nacional y la ausencia de una cultura empresarial competitiva ${ }^{5}$.

En el ámbito global, varios factores y fenómenos como las restricciones al gasto público, los requerimientos de inversión social y la crisis financiera han incrementado el interés en las compras públicas y cómo lograr que resulten costo eficientes. Como portadores de tal interés, se destacan varios organismos internacionales y multilaterales, como la Comisión Económica para América Latina y el Caribe, CEPAL; la Comunidad Andina, CAN; el Banco Mundial; la Organización para la Cooperación y el Desarrollo Económicos, OCDE; y la Conferencia de Naciones Unidas para el Comercio y el Desarrollo, UNCTAD 6 .

En líneas generales, la colusión consiste en la práctica entre competidores de concertación de una conducta cuyo propósito es maximizar el beneficio económico de todos por medio de la elusión de la competencia. El fenómeno de la colusión en compras públicas

4 Ting Gong \& Na Zhou, Corruption and Marketization: Formal and Informal Rules in Chinese Public Procurement, 9 Regulation \& Governance, 1, 63-76, 64 (2015). Disponible en: https://www. researchgate.net/publication/261141803_Corruption_and_marketization_Formal_and_informal_ rules in Chinese public procurement

5 Sobre la relación entre desarrollo económico y eficacia del derecho de competencia: "Lo anterior confirma la tesis que establece que la eficacia de las normas protectoras de la libre competencia está directamente vinculada con la existencia de una industria moderna, suficiente y generadora de valor, pues de lo contrario los procesos de comercialización estarán encaminados a producir más daños que beneficios, especialmente deprimiendo ciertos sectores productivos por la falta de estímulos al desarrollo y coartando la posibilidad de consolidación de las pequeñas y medianas empresas". Stefan E. Weishaar, Cartels, Competition and Public Procurement. Law and Economics Approaches to Bid Rigging, 252 (Edward Elgar Publishing, Cheltenham, 2013).

6 Entre los autores latinoamericanos que han destacado el protagonismo de los organismos internacionales y multilaterales en la construcción de institucionalidad en materia de derecho de competencia, debe citarse a Luis Fernando Álvarez-Londoño, S.J., Últimas tendencias en derecho de la competencia en América Latina, 115 Vniversitas, 247-262, 250 (2008). Disponible en: http://revistas. javeriana.edu.co/index.php/vnijuri/article/view/14584/11766 
se enmarca en el derecho de competencia, que constituye una norma de carácter especial, cuyo objeto de regulación es la actividad concurrencial en el ámbito económico, y se rige por el principio homónimo de competencia, el cual dispone que la interacción entre competidores en un mercado se realice con la lealtad que cabe esperar en el comercio. De este modo, el propósito del derecho de competencia desde su surgimiento ha sido proveer un marco regulatorio para la actuación de los operadores del mercado con el propósito de consagrar igual oportunidad de colocar un producto o servicio para el consumidor. En este sentido, el derecho de competencia encuentra importante conexión con las ciencias económicas?

\section{ACUERDOS ANTICOMPETITIVOS}

Los acuerdos anticompetitivos constituyen un género de conductas restrictivas de la competencia consistente en contratos, convenios, prácticas concertadas o conscientemente paralelas que prevengan, restrinjan o distorsionen la competencia o que potencialmente provoquen tales efectos. Las tesis en torno a los acuerdos anticompetitivos se desarrollan a partir de la teoría de los costos de transacción de Ronald Coase de $1937^{\circ}$. No obstante, no todos los acuerdos entre competidores con efecto restrictivo de la competencia son ilegítimos. En este sentido, deben distinguirse los acuerdos anticompetitivos per se —naked agreements - y los acuerdos que se consideran socialmente útiles - ancillary restraints — 9 .

Los acuerdos que se consideran anticompetitivos son de la más diversa índole y naturaleza, incluso los celebrados entre competi-

7 Junto a la tendencia hacia el carácter global del derecho de competencia y la pérdida de su territorialidad, debe mencionarse la tendencia hacia un mayor apoyo en los conceptos de las ciencias económicas. En este sentido, resultan muy elocuentes Einer Elhauge y Damien Geradin: "El moderno derecho de competencia difiere del tradicional en que actualmente refleja la dominación de modelos económicos de análisis de las políticas de competencia y antimonopolio. Este cambio ha ocurrido tanto en Estados Unidos como en la Unión Europea, donde con anterioridad los modelos legales incluían nociones de competencia políticas, formalistas, corporativistas o basadas en la autonomía privada". Einer Elhauge \& Damien Geradin, Global Antitrust Law and Economics, v (Foundation Press, Thomson Reuters, New York, 2011).

8 Ronald Coase, The Nature of the Firm, 4 Economica. Blackwell Publishing, 16, 386-405 (1937). doi:10.1111/j.1468-0335.1937.tb00002.x. Disponible en: http://www.colorado.edu/ibs/es/alston/ econ $4504 /$ readings/The $\% 20$ Nature $\% 20$ of $\% 20$ the $\% 20$ Firm $\% 20$ by $\% 20$ Coase.pdf

9 JAVIER TAPIA, Carácter anticompetitivo de los acuerdos restrictivos de la competencia en el sector retail, aludiendo a Robert H. Bork y Herbert Hovenkamp (2009). Disponible en: http://papers.ssrn. com/sol3/papers.cfm?abstract_id=1440695 
dores para la coordinación de acciones y política de $\mathrm{I}+\mathrm{D}+\mathrm{i}$ bajo la forma de joint venture ${ }^{10}$. Estos se clasifican según los sujetos que forman parte del mismo, según el objeto o la materia sobre la que recae el acuerdo y según la forma que adoptan.

\section{A. Acuerdos anticompetitivos horizontales y verticales}

De acuerdo a los sujetos, los acuerdos pueden ser horizontales o verticales ${ }^{11}$. En el primer caso, se trata de acuerdos entre empresas ubicadas en el mismo nivel de la cadena del producto o servicio, o de productos similares o sustitutos. Por su parte, los acuerdos verticales son aquellos que se suscriben entre empresas ubicadas en posiciones diferentes dentro de la cadena productiva, en los cuales el fabricante impone el precio de venta final al distribuidor, entre otras condiciones. Este tipo de acuerdos tiene un tratamiento normativo más favorable, a diferencia de los acuerdos horizontales, dado que pueden resultar funcionales a la eficiencia, la productividad y la generación de economías de escala, con el consiguiente efecto beneficioso para el consumidor final.

Los acuerdos verticales no recibieron atención de inicio por el derecho de competencia en la Unión Europea, al punto de no distinguirse respecto de los acuerdos horizontales ${ }^{12}$. A partir de los años 70, y como resultado de la influencia de las tesis de la Escuela de Chicago y de determinadas decisiones de la Corte Suprema de Estados Unidos, las instituciones europeas comienzan a otorgar

10 JAVIER TAPIA, Carácter anticompetitivo de los acuerdos restrictivos de la competencia en el sector retail, 7 (2009).

11 Un sector de la doctrina anglosajona se opone a esta clasificación: William F. Baxter y Daniel P. Kessler; por su parte, Mark A. Lemley y Christopher R. Leslie consideran que la distinción es útil en razón a un criterio de eficiencia judicial. JAVIER TAPIA, Carácter anticompetitivo de los acuerdos restrictivos de la competencia en el sector retail, 4-6 (2009).

12 En los casos LTM/MBU (Corte Europea de Justicia, Caso 56/65, Société Technique Minière, LTMv. Maschinenbau Ulm GmbH, MBU, 30 de junio de 1966, ECR 337), Consten \& Grundig (Corte Europea de Justicia, Caso 58/64, Etablissements Consten SARL \& Grundig-Verkaufs-GmbH v. Commission, 13 de julio de 1966, ECR 299) y República Italiana vs. Comisión (Corte Europea de Justicia, Caso 32/65, República Italiana contra Comisión, 13 de julio de 1966, ECR 407), a pesar de la opinión del abogado general Jürgen Roemer, el Tribunal de Justicia de la Unión Europea, TJUE, no delineó ningún género de distinción entre acuerdos horizontales y verticales, e ignoró los últimos. IoANNIS Lianos, Collusion in Vertical Relations under Article 81 EC, 45 Common Market Law Review, 4, 1027-1077, 1030 (2008). Disponible en: https://papers.ssrn.com/sol3/papers.cfm?abstract_id=1089 $681 \&$ rec $=1 \&$ srcabs $=1724891 \&$ alg $=1 \&$ pos $=1$ 
mayor atención a la distinción entre acuerdos horizontales y verticales $^{13}$. En este caso, la distinción cobró importancia especial, dado que la consecuencia sería el tratamiento diferenciado de ambos tipos de acuerdos: a los acuerdos horizontales se les aplica la regla per se, mientras que a los acuerdos verticales se les aplica la regla de la razón ${ }^{14}$. Esta distinción, de inicio esporádica, se convirtió en una tendencia sistemática en la jurisprudencia no solo de Estados Unidos sino europea, a partir de un movimiento reformador del derecho de competencia a finales de la década de los noventa y les otorgó un tratamiento más displicente y tolerante a los acuerdos verticales respecto de los horizontales ${ }^{15}$.

Los acuerdos verticales ameritan un análisis pormenorizado pues puede tratarse de un caso de concentración económica o de auténtica subordinación empresarial a un solo sujeto en el mercado $^{16}$. En razón de ello y a medio camino entre los acuerdos

13 En particular, en los casos Sylvania (Estados Unidos, Suprema Corte, Continental T.V. Inc. v. GTE Sylvania Inc., 433 US 36, June 23, 1977), State Oil v. Khan (Estados Unidos, Suprema Corte, State Oil v. Khan, 522 US 3, November 4, 1997) y Leegin (Estados Unidos, Suprema Corte, Leegin Creative Leathers Products, Inc. v. PSKS, Inc., 127 S Ct 2705, June 28, 2007), en los cuales la Corte Suprema y demás tribunales, de diversas maneras, sostuvieron tesis similares en el sentido de que el análisis en torno a la viabilidad de los acuerdos verticales ha de ser conforme a la regla de razón respecto del efecto anticompetitivo. Ioannis Lianos, Collusion in Vertical Relations under Article 81 EC, 45 Common Market Law Review, 4, 1027-1077, 1031 (2008).

14 Ioannis Lianos, Collusion in Vertical Relations under Article 81 EC, 45 Common Market Law Review, 4, 1027-1077, 1031 (2008).

15 El rigor aplicado por la Comisión Europea a los acuerdos verticales por debajo del sostenido contra los acuerdos horizontales está motivado por el fenómeno de autopolicía. Este se caracteriza por la vigilancia que establece la propia empresa asociada en el acuerdo vertical para que su contraparte no ejerza el poder de mercado, y afecte la demanda como resultado de este ejercicio de este poder. Esto no ocurre en los acuerdos horizontales, los cuales presentan una dinámica ganar-ganar para todos los asociados, pues el efecto útil del acuerdo consiste en el incremento del margen de utilidades de todos los participantes. En este último caso no hay incentivo para socavar o reprimir el ejercicio de poder de mercado. IoAnNis Lianos, Collusion in Vertical Relations under Article 81 EC, 45 Common Market Law Review, 4, 1027-1077, 1032 (2008).

16 El precedente relevante en Estados Unidos según el tipo de acuerdos es amplio: en materia de ventas exclusivas - exclusive dealing-, deben mencionarse los siguientes casos: US v. Griffith (Estados Unidos, Suprema Corte, United States v. Griffith, 334 US 100, May 3, 1948); Standard Fashion v. Magrane-Houston (Estados Unidos, Suprema Corte, Standard Fashion Co. v. Magrane-Houston Co., 258 US 346, April 10, 1922); Standard Oil and Standard Stations v. US (Estados Unidos, Suprema Corte, Standard Oil Co. v. United States, 337 US 293 (June 13, 1949); FTC v. Motion Picture Advertising Service (Estados Unidos, Suprema Corte, Federal Trade Commission, FTC v. Motion Picture Advertising Svc. Co., Inc., 344 US 392, February 2, 1953); Tampa Electric v. Nashville Coal (Estados Unidos, Suprema Corte, Tampa Electric Co. v. Nashville Coal Co., 365 US 320, February 27, 1961) y por último, US v. Microsoft (Estados Unidos, Corte de Apelaciones para el Circuito del Distrito de Columbia, United States v. Microsoft Corporation, 253 F.3d 34, D.C. Cir., June 28, 2001). En el caso de ventas atadas — tying - los siguientes casos: Jefferson Parish Hospital $v$. Hyde (Estados Unidos, Suprema Corte, Jefferson Parish Hospital District No. 2 v. Hyde, 466 US 2, March 27, 1984); Eastman Kodak v. Image Technical Service (Estados Unidos, Suprema Corte, 
anticompetitivos horizontales y la concentración económica, se desarrolla actualmente una preocupante tendencia global hacia la generalización de un fenómeno contrario en su esencia a la competencia y difícil de tipificar.

\title{
B. El reciente fenómeno de la participación accionaria horizontal, horizontal shareholding
}

\begin{abstract}
Se trata del efecto anticompetitivo que se deriva de la participación accionaria horizontal de un grupo reducido de inversionistas institucionales ${ }^{17}$. Para ser más exactos, consiste en el fenómeno por el cual las principales empresas en un mercado relevante cuentan en su estructura accionaria con un número determinado y muy reducido de inversionistas comunes con una cuota de participación sustancial ${ }^{18}$. Este fenómeno no califica como concentración
\end{abstract}

Eastman Kodak Co. v. Image Technical Servs., Inc., 504 US 451, June 8, 1992); Illinois Tool Works $v$ Independent Ink, Inc. (Estados Unidos, Suprema Corte, Illinois Tool Works Inc. v. Independent Ink, Inc., 547 US 28, March 1, 2006); y una vez más, US v. Microsoft. Para el caso europeo, consúltense la Decisión 88/138/CEE (Comisión Europea, Decisión 88/138/CEE, Eurofix Bauco contra Hilti, comisionado Peter Sutherland, 22 de diciembre de 1987); la Decisión 92/163/CEE (Comisión Europea, Decisión 92/163/CEE, TetraPak II, comisionado presidente José Luis da Cruz-Vilaça, 24 de julio de 1991) y el caso T-201/04 (Tribunal de Justicia de las Comunidades Europeas, Sala Plena, Microsoft v. Comisión, Asunto T-201/04, magistrado presidente Bo Vesterdorf, 17 de septiembre de 2007). La presente y sucesivas alusiones al precedente estadounidense y a la jurisprudencia comunitaria europea tienen como fuente a Elhauge \& Geradin. Einer Elhauge \& Damien Geradin, Global Antitrust Law and Economics (Foundation Press, Thomson Reuters, New York, 2011).

17 Este fenómeno de reciente interés académico recibe varias denominaciones: titularidad paralela de inversionistas institucionales en industrias concentradas — parallel holdings of institutional investors in concentrated industries -; titularidad común de inversionistas institucionales — common holdings of institutional investors - (Ken DAvidson, Elhauge, Read the Wrong Way?), titularidad cruzada — cross-holdings_, entre otras. Baker se opone a la denominación de participación horizontal, propuesta por Elhauge y a su vez propone denominar el fenómeno como titularidad superpuesta de inversionistas financieros — Overlapping Financial Investor Ownership —. Por otra parte, Steven Salop y Daniel O'Brien denominan el fenómeno como titularidad parcial por rivales horizontales, Partial Ownership by Horizontal Rivals. Steven Salop \& Daniel O'Brien, Competitive Effect of Partial Ownership: Financial Interest and Corporate Control, 67 Antitrust Law Journal, 559-614 (2000). Disponible en: http://scholarship.law.georgetown.edu/cgi/viewcontent.cgi?article=1200\&c ontext $=$ facpub. Al respecto, véase por todos, Jonathan B. BAKER, Overlapping Financial Investor Ownership. Market Power and Antitrust Enforcement: My Qualified Agreement with Professor Elhauge, 129 Harvard Law Review Forum, 212-232 (2016). Disponible en: https://harvardlawreview. org/2016/03/overlapping-financial-investor-ownership-market-power-and-antitrust-enforcementmy-qualified-agreement-with-professor-elhauge/

18 Elhauge describe elocuentemente el fenómeno a partir de datos empíricos: en el mercado de aerolíneas, siete inversionistas controlan cuotas significativas en United Airlines, Delta Airlines, JetBlue Airlines y Southwest Airlines, que a su vez detentan una cuota más que significativa del mercado relevante. En el mercado de la banca, cuatro inversionistas (BlackRock, Vanguard, State Street y Fidelity) son titulares de cuotas relevantes de participación accionaria en JPMorgan Chase, Bank of America y Citigroup, que a su vez tienen una cuota nada despreciable en el sector bancario. Lo 
económica en sentido propio pues no se trata de una fusión o de un conglomerado de entidades controladas, sino como participación accionaria horizontal o simplemente participación cruzada ${ }^{19}$. El actual marco normativo antimonopólico impide su represión dada la dificultad para su tipificación, lo que genera un posible conflicto con la libre adquisición y venta de títulos en una economía de libre mercado. No llega a ser una concentración económica propiamente dicha pero tampoco integra una conducta colusoria propia; está a mitad de camino entre uno y otro.

La estrategia de persecución asumida por parte de las agencias especializadas en Estados Unidos ha sido aumentar la lupa de la investigación y perseguir la colusión por medio de la fijación de precios, lo cual constituye la conducta típica de los competidores involucrados en este fenómeno. Dicho esto, los inversionistas institucionales encuentran excelentes incentivos para evitar una guerra de precios, reducir sus actividades de $\mathrm{I}+\mathrm{D}+\mathrm{i}$ y cooperar activamente en la fijación de precios, aunque no resulta del todo necesario. De igual forma, encuentran excelentes incentivos para minar por medios deshonestos la actividad de un competidor nuevo o no participado por el grupo de inversionistas institucionales que pretenda incrementar su cuota de mercado con conductas competitivas como la reducción de precios, el incremento del suministro a la demanda o el valor tecnológico añadido ${ }^{20}$.

Como resultado, los autores citados reportan auténticas prácticas anticompetitivas como colusión y follow the price leader ${ }^{21}$.

mismo ocurre en el mercado relevante de farmacias y de software para PC. EINER ElHAUGE, Horizontal Shareholding, 129 Harvard Law Review, 1267-1317, 1268 (2016). Por su parte, Baker describe el fenómeno en los mismos mercados. Jonathan B. BAKer, Overlapping Financial Investor Ownership. Market Power and Antitrust Enforcement: My Qualified Agreement with Professor Elhauge, 129 Harvard Law Review Forum, 212-232, 213 (2016).

19 La descripción precisa de este fenómeno se puede encontrar en dos textos de reciente publicación, uno de carácter académico: Einer Elhauge, Horizontal Shareholding, 129 Harvard Law Review, 1267-1317 (2016), y otro de carácter más bien periodístico o de comentario económico: DeVANGSHU DATTA, Investing in Peer Stocks, Business Standard News (August 2 ${ }^{\text {nd }}, 2015$ ). Disponible en: http:// www.business-standard.com/article/pf/investing-in-peer-stocks-115080200784_1.html

20 Esta conducta es producto de un fenómeno de concentración económica no definido como tal por la ley, pero la evidencia empírica demuestra su existencia al obtenerse un Índice Herfindahl-Hirschman por encima de 2500: el actual umbral de concentración admitido por las autoridades de competencia en Estados Unidos. Einer Elhauge, Horizontal Shareholding, 129 Harvard Law Review, 1267-1271 (2016).

21 Baker da cuenta de varios estudios empíricos que sostienen el incremento de conductas facilitadoras de coordinación y prácticas restrictivas de la competencia así como de exclusión o prevención de entrada de competidores. JonATHAn B. BAKer, Overlapping Financial Investor Ownership. Market 
El secreto a voces consiste en que tales inversionistas ejercen su derecho a voto conforme su mejor interés empresarial y asistidos por la administración. El gestor de cada empresa por separado recomienda a los accionistas una conducta anticompetitiva dada la información pública de que tales accionistas participan también en las empresas competidoras ${ }^{22}$. He aquí entonces dos hechos inevitables e irreprimibles por la ley: el carácter público de la información sobre la estructura accionaria de los competidores en el mercado y el ejercicio del derecho al voto por los accionistas en su mejor interés empresarial; añádase la exención a las adquisiciones con único propósito de inversión, dispuesta en la Ley Clayton ${ }^{23}$. Estos son los elementos que crean el marco propicio para una férrea resistencia a la competencia en un mercado con escasos competidores y participación accionarial cruzada por un grupo reducido de inversionistas.

Este fenómeno, en particular estadounidense, es de singular importancia para América Latina, región donde el carácter primarioexportador de las economías y otras vulnerabilidades estructurales tienen por efecto un mayor número de mercados con escasos competidores y una más intensa participación como inversionista de grupos económicos institucionales de raíz familiar. Se han identificado al menos tres efectos, negativos para los mercados relevantes en Estados Unidos y muy nocivos para América Latina. En primer lugar, recompensa a la administración no por los resultados de la empresa sino de la industria en general. En segundo lugar, explica cómo es posible que los incentivos fiscales y estímulos económicos a las empresas no se reviertan en incremento del I+D+i, de la producción y del empleo ${ }^{24}$. En tercer lugar, promueve la inequidad en

Power and Antitrust Enforcement: My Qualified Agreement with Professor Elhauge, 129 Harvard Law Review Forum, 212-232, 215 (2016).

22 Dicho en términos más explícitos: "Si existe una sustancial participación accionaria horizontal, los incentivos [a competir] se reducen. La administración de las empresas pares participadas no necesitan coludir o cartelizarse. Su estrategia es determinada por retroalimentación proveniente de los principales accionistas-inversionistas quienes tienen posiciones en varias de las empresas". Devangshu Datta, Investing in Peer Stocks, Business Standard News (August $2^{\text {nd }}, 2015$ ). Sobre el tema resulta igualmente relevante: Ken Davidson, Elhauge, Read the Wrong Way? (9 de agosto de 2015).

23 Estados Unidos, Clayton Antitrust Act, 15 USC $\S \S 12-27,29$ USC $\S \S 52-53$. Disponible en: http:// gwclc.com/Library/America/USA/The\%20Clayton\%20Act.pdf

24 Estos son los aspectos que motivan la necesidad de una política y norma de derecho de competencia en América Latina ajustadas a la realidad de la región: "En conclusión, las economías de países en vía de desarrollo son portadoras de estructuras de mercado con características muy propias, y 
la distribución de la riqueza, lo que mina la capacidad adquisitiva del consumidor ${ }^{25}$.

\section{Acuerdos anticompetitivos de carácter expreso, tácito o presunto}

Los acuerdos expresos reciben la denominación de cartel, y el fenómeno por el cual las empresas competidoras en un mercado relevante alcanzan acuerdos anticompetitivos de modo expreso se denomina cartelización. No obstante, varios autores coinciden en sostener la denominación de cartel para los acuerdos tácitos (entre los que restringe el cartel a los acuerdos expresos) ${ }^{26}$. En derecho anglosajón, los acuerdos expresos reciben el nombre de agreement, mientras los acuerdos tácitos reciben la denominación de understanding ${ }^{27}$.

Usualmente, los esfuerzos conceptuales enfocan el objeto del cartel, no su forma. En este sentido, definen como tal los acuerdos entre competidores que tienen por objeto evitar la competencia mediante la autorregulación de la producción, la venta o el precio ${ }^{28}$. Entre los presupuestos para determinar la existencia de un cartel deben mencionarse las barreras de entrada, cuya inexistencia elimina el

sobre las que la política de competencia debe actuar de forma diferente de su accionar en economías más perfectas. Por ejemplo, un gran número de las economías latinoamericanas carecen de cultura de competencia; poseen una importante concentración del poder económico y político en pocas manos que les permite a las organizaciones capturar las instituciones y de otro lado dificulta la independencia de las autoridades; tampoco poseen, desde la perspectiva de los Estados, los recursos financieros y humanos para consolidar instituciones sólidas que actúen contra los comportamientos anticompetitivos; hechos todos que unidos generan una mezcla perfecta para capturar los beneficios de la apertura económica por unos pocos e incrementar las diferencias económicas y sociales entre los ciudadanos". Luis Fernando Álvarez-Londoño, S.J., Últimas tendencias en derecho de la competencia en América Latina, 115 Vniversitas, 247-262, 256 (2008).

25 Einer Elhauge, Horizontal Shareholding, 129 Harvard Law Review, 1267-1272, 1272 (2016).

26 JAVIER TAPIA, Carácter anticompetitivo de los acuerdos restrictivos de la competencia en el sector retail, 6 (2009).

27 Sin negar lo expuesto, Louis Kaplow y Carl Shapiro hacen referencia indistintamente a colusión y cartel. Sin declararlo expresamente, se infiere que cartel es el acuerdo en sí, mientras que la colusión es el efecto restrictivo en la competencia provocado por el cartel (cartel agreement, collusive outcome, collusive behavior); en cualquier caso, no hay una distinción clara. LoUIS KAPLOw \& CARL Shapiro, Antitrust (John M. Olin Center for Law, Economics and Business, Harvard Law School Discussion Paper 01/2007, 2007). http://www.law.harvard.edu/programs/olin_center/papers/pdf/ Kaplow_695.pdf

28 Lianos apunta a un concepto de acuerdo no enfocado en la forma sino en la intención de las partes: intercambio formal o informal de comunicación de garantía u oferta + aceptación que pueda probar la existencia de una común intención entre las partes. IoAnNis Lianos, Collusion in Vertical Relations under Article 81 EC, 45 Common Market Law Review, 4, 1027-1077, 1027 (2008). 
carácter restrictivo del acuerdo, al admitir el ingreso de nuevos oferentes. Otro de los presupuestos es el bajo impacto relativo en el mercado de las decisiones de producción de los productores no miembros del cartel.

Los acuerdos anticompetitivos de carácter tácito se corresponden de modo más o menos exacto a la categoría de la colusión. Se distinguen del cartel en que, si bien ambos tienen naturaleza convencional, la colusión no necesariamente constituye un acuerdo formal sino que puede y de hecho reviste carácter tácito ${ }^{29}$. Por su parte, algunas autoridades de la competencia resaltan el carácter anticipatorio a la conducta legalmente reprobable, como la práctica de concertación anticipada de las condiciones de actuación en el mercado, con el propósito de competir o excluir a otros competidores potenciales ${ }^{30}$.

Dentro del concepto de colusión deben mencionarse las prácticas concertadas como acuerdo tácito entre empresas para restringir la competencia, las cuales se determinan por medio de hechos concluyentes - facta concludentia — ${ }^{31}$. La distinción entre acuerdo expreso y práctica concertada se manifestó en el caso europeo Polypropylene,

29 En este sentido, la Ley Federal de Competencia Económica de México de 1992, art. 9: Prácticas Monopólicas Absolutas o acuerdos colusorios, las define como contratos o acuerdos entre competidores, que tengan por objeto o efecto la fijación de precios, obligación de restricción de la oferta, distribución de mercados, "establecer o coordinar posturas en licitaciones, concursos, subastas o almonedas públicas". La ley federal mexicana establece expresamente el acuerdo entre postores ante concurso como un tipo específico de colusión, más allá del objeto, contenido o alcance del acuerdo: Jorge WitKer, Derecho de la competencia en América, Canadá, Chile, Estados Unidos y México (Fondo de Cultura Económica, FCE, 2000).

30 Colombia, Superintendencia de Industria y Comercio, Resolución 1055 de 2009, Caso Intersystem, Buitrago Camargo y Vega Cruz, 19 de enero de 2009. Disponible en: http://www.sic.gov.co/recursos_user/documentos/normatividad/Publicaciones_Despacho_3/sicdecisiones2/RESOLUCIONES _COMPETENCIA_ANOS/2009/RESOLUCION_1055_DE_19_DE_ENERO_DE_2009_SANCION INTERSYSTEM.pdf

31 La distinción entre acuerdo y práctica concertada se determina a partir de la forma que adopta la conducta de las empresas involucradas. Lianos sostiene que la distinción radica en la evidencia: el acuerdo expreso es aquel que resulta demostrable por medio de evidencia directa, mientras que las prácticas concertadas son aquellas que solo pueden probarse con evidencia circunstancial. IoANNIS Lianos, Collusion in Vertical Relations under Article 81 EC, 45 Common Market Law Review, 4, 1027-1077, 1027 (2008). 
1986 32; ya desaparece en el caso PVC II, 1994 ${ }^{33}$, al establecer como relevante la distinción entre acuerdos colusorios y no-colusorios, a partir del argumento de que en muchas ocasiones ambos tipos de prácticas - concertadas o expresas - aparecen mezclados en una misma conducta objeto de prohibición ${ }^{34}$. El caso Dyestuffs en 1972 dispuso que solo es considerable como práctica concertada aquella que tiene por efecto un equilibrio en los precios favorable a los competidores en conjunto y que hubiese sido imposible sin ese comportamiento ${ }^{35}{ }^{36}$. Las prácticas concertadas en el ámbito de los acuerdos verticales han sido asociadas al menos a dos de las siguientes conductas: una aparente acción unilateral en ejecución

32 Comisión Europea, Decisión 86/398/EEC, relating to a proceeding under Article 85 of the EEC Treaty (IV/31.149 - Polypropylene), April 23, 1986. Disponible en: http://eur-lex.europa.eu/legal-content/ EN/TXT/?uri=OJ:L:1986:230:TOC. Corte Europea de Justicia, Case 213/86 R, Montedipe SpA v. Commission of the European Communities (Polypropylene case), September 24, 1986. Disponible en: http://curia.europa.eu/juris/showPdf.jsf;jsessionid=9ea7d2dc30dbd33e849eec9d45fabaeb82522 fda9725.e34KaxiLc3qMb40Rch0SaxuLchf0?text=\&docid=94992\&pageIndex=0\&doclang=en\&m ode $=1$ st \&dir $=\&$ occ $=$ first $\&$ part $=1 \&$ cid $=439178$

33 Comisión Europea, Decisión 94/599/EC, relativa a un procedimiento de aplicación del artículo 85 del Tratado CE (IV/31.865, PVC), 27 de julio de 1994. Disponible en: http://eur-lex.europa.eu/ legal-content/EN/TXT/?uri=CELEX\%3A31994D0599

34 En este sentido, los casos NV Limburgse, 1999 (Corte Europea de Justicia, Limburgse Vinyl Maatschappij NV, Elf Atochem SA, BASF AG, Shell International Chemical Company Ltd, DSM NV, DSM Kunststoffen BV, Wacker-Chemie GmbH, Hoechst AG, Société Artésienne de Vinyle, Montedison $S p A$, Imperial Chemical Industries Plc, Hüls AG and Enichem SpA v. Commission, Caso T-305/94, 2 de abril de 1999) y Rhone-Poulenc, 1991 (Corte Europea de Justicia, Sala Sexta, Rhone-Poulenc v. Commission, Caso T-1/89, 24 de octubre de 1991). Continúa la clasificación conjunta de acuerdo expreso y práctica concertada en Cartonboard, 1994 (Comisión Europea, Decisión 94/601/CE, relativa a un procedimiento de aplicación del artículo 85 del Tratado CE (IV/C/33.833 - cartoncillo - Cartonboard), 13 de julio de 1994); British Sugar, 1999 (Comisión Europea, Decisión 99/210/CE, relativa a un procedimiento con arreglo al artículo 85 del Tratado CE (asuntos $I V / F-3 / 33.708-$ British Sugar Plc, IV/F-3/33.709 — Tate \& Lyle Plc, IV/F-3/33.710 - Napier Brown \& Company Ltd y IV/F-3/33.711 — James Budgett Sugars Ltd), 13 de julio de 1994); y Preinsulated Pipe Cartel, 1999 (Comisión Europea, Decisión 1999/60/CE, relativa a un procedimiento con arreglo al artículo 85 del Tratado CE (IV/35.691/E-4: Cartel en el mercado de los tubos preaislados - Pre-Insulated Pipe Cartel), 21 de octubre de 1998). En cualquier caso, la definición en el caso 48/69, Imperial Chemical Industries Ltd v. Comisión, 1972 ECR 619 (Corte Europea de Justicia, Sala Primera, Asunto 48/69, Imperial Chemical Industries, ICI Ltd. v. Commission, Dyestuffs, magistrado Robert Lecourt, 14 de julio de 1972) resulta elocuente por sí misma, en el sentido de tener por propósito la prohibición de cierta forma de coordinación entre empeños anticompetitivos incluso en actos preparatorios, sin alcanzar el nivel de un auténtico acuerdo, y durante el cual las partes involucradas en ese empeño sustituyen la competencia con la cooperación. IoAnnis Lianos, Collusion in Vertical Relations under Article 81 EC, 45 Common Market Law Review, 4, 1027-1077, 1051 (2008).

35 JAVIER TAPIA, Carácter anticompetitivo de los acuerdos restrictivos de la competencia en el sector retail, 48 (2009).

36 En igual sentido, en el asunto Brooke Group, 1993 (Estados Unidos, Suprema Corte, Brooke Group Ltd. v. Brown \& Williamson Tobacco Corp., 509 US 209, June 21, 1993), la Corte Suprema estadounidense sostiene que la colusión tácita no es en sí misma ilegal. 
de un acuerdo vertical preexistente y acuerdos entre suministrador y distribuidor ${ }^{37}$.

Por último, debe hacerse alusión a los actos presuntos, que son las conductas conscientemente paralelas ${ }^{38}$, como los actos unilaterales de un competidor en relación con el comportamiento de otros competidores, con lo cual no llega a ser una forma de coordinación, menos aún un acuerdo. No obstante, se tienen por acuerdos anticompetitivos que se derivan de un comportamiento del mercado que no puede ser explicado fuera de la existencia de una conducta de los competidores encaminada a la restricción de la competencia, por lo que se presume la existencia del acuerdo anticompetitivo ${ }^{39}$. En esta categoría de práctica anticompetitiva, el derecho anglosajón reconoce la distinción entre acuerdo anticompetitivo tácito — tacit collusion - y presunto - conscious parallelism — ${ }^{40}$.

Un ejemplo de este tipo de conductas es el caso Wood Pulp ante la Comisión Europea. La misma declaró la existencia de colusión, a pesar de no haber evidencia expresa; en tal caso, se presumió la existencia de este acuerdo por los intercambios de información y por el hecho de que el mercado relevante no era proclive a la presencia de precios paralelos. Las conductas paralelas no son restrictivas de la competencia per se ni prohibidas, no hay concertación si puede ser explicada por el mercado. En el asunto Suiker Unie ${ }^{41}$, el TJCE

37 Un ejemplo es el caso Dunlop Slazenger (Corte Europea de Justicia, Sala Segunda, Dunlop Slazenger International Ltd v. Commission, Asunto T-43/92, 7 de julio de 1994), consistente en la prohibición general de exportación dispuesta por la empresa a sus distribuidores, junto a una serie de medidas para garantizar la eficacia de esta disposición: rehúse de suministro para exportaciones paralelas, manejo de precios para suprimir competitividad a las exportaciones potenciales de los distribuidores, recompra de productos exportados por canales paralelos, marcaje de productos para determinar la fuente de las importaciones paralelas, entre otras. IoAnnis Lianos, Collusion in Vertical Relations under Article 81 EC, 45 Common Market Law Review, 4, 1027-1077, 1052, 1053 (2008).

38 También denominadas paralelismo inconsciente o casual, paralelismo estructural, paralelismo consciente propio, paralelismo consciente colusorio.

39 Estados Unidos, Suprema Corte, United States v. E. I. du Pont de Nemours \& Co., caso celofán, 351 US 377 (June 11, 1956). Disponible en: https://supreme.justia.com/cases/federal/us/351/377/

40 Una de las formas que adopta este tipo de conducta es la coordinación oligopolística: "Algunos mercados tienen escasas empresas de modo que tienen una influencia en los precios y las ventas y pueden y de hecho responden a las acciones de otras empresas en el mismo mercado. En tal caso, aún sin un acuerdo explícito, tales empresas pueden coordinar esfuerzos para restringir las ventas y levantar los precios. Esto se denomina coordinación oligopolística. La gran dificultad que plantea es si la coordinación puede ser condenada sin pruebas de un acuerdo, especialmente cuando las empresas oligopólicas no pueden evitar saber que sus políticas y decisiones de precios y ventas afectarán el comportamiento de otras empresas". Einer Elhauge \& Damien Geradin, Global Antitrust Law and Economics, 3 (Foundation Press, Thomson Reuters, New York, 2011).

41 Corte Europea de Justicia, Sala Plena, Suiker Unie, Asunto 40/73, magistrado presidente Robert Lecourt, 16 de diciembre de 1975. Disponible en: http://curia.europa.eu/juris/liste. 
dispuso que la conducta paralela solo alcanza rango de colusión, si la concertación constituye la única explicación plausible.

Se le reconocen dos requisitos. Uno objetivo que alude al intento por los competidores de limitar la competencia y otro que alude a la necesaria producción de un efecto restrictivo aun cuando no sea intencional. Sin embargo, en la antitrust law, las conductas conscientemente paralelas suponen un elemento probatorio adicional o plus factor. La necesidad de este plus factor para configurar una conducta conscientemente paralela como modalidad de colusión ha sido un criterio establecido por Theatre Enterprises Inc..$^{42}$ y posteriormente confirmado en Blomkest Fertilizer, 2000 ${ }^{43}$, Petroleum Products (1990) ${ }^{44}$ y $A T P(1993)^{45}$.

Uno de los principales problemas que plantean las conductas anticompetitivas es el de su prueba, que dependerá del tipo de acuerdo restrictivo de la competencia, sea expreso, tácito o presunto. En los acuerdos expresos se requerirá prueba de la celebración de ese acuerdo entre los competidores. En los acuerdos tácitos, se requerirá solamente prueba de los hechos concluyentes que implican razonablemente un entendimiento entre las partes. Por último, el acuerdo presunto no requiere evidencia pues implica una virtual inversión de la carga de la prueba por medio de la cual las partes objeto de investigación o decisión han de demostrar que la conducta conscientemente paralela es explicable fuera de un hipotético acuerdo entre ellos.

Otro de los problemas es la obtención del material probatorio, dado que se trata de documentación y hechos internos de las em-

jsf?language $=$ en\&num $=40 / 73$

42 Estados Unidos, Suprema Corte, Theatre Enterprises Inc. v. Paramount Film Distributing Corp., 346 US 537 (1954). Disponible en: https://supreme.justia.com/cases/federal/us/346/537/case.html

43 Estados Unidos, Corte de Apelaciones del 8 Circuito, Blomkest Fertilizer, Inc. v. Potash Corp. of Saskatchewan, Inc., 203 F.3d 1028, $8^{\text {th }}$ Circ. (February 17, 2000). Disponible en: https://h2o.law. harvard.edu/collages $/ 35782$

44 JAVIER TAPIA, Carácter anticompetitivo de los acuerdos restrictivos de la competencia en el sector retail, 50 (2009). William Kovacic \& Carl Shapiro, Antitrust Policy: A Century of Economic and Legal Thinking, 14 Journal of Economic Perspectives, 1, $43-60$ (2000). Disponible en: http://faculty. haas.berkeley.edu/shapiro/century.pdf

45 "El comportamiento paralelo no puede ser considerado en sí mismo anticompetitivo si encuentra su explicación en las condiciones del mercado, el cual debe ser analizado con meticuloso detalle. Solamente si el paralelismo tiene como única explicación una concertación (esto es, si no es la clase de comportamiento que debiera esperarse en el mercado en cuestión), él puede ser usado como base para condenar". JAVIER TAPIA, Carácter anticompetitivo de los acuerdos restrictivos de la competencia en el sector retail, 49 (2009). 
presas, que guardan celosamente la confidencialidad de sus operaciones y comunicación organizacional, además de guardar una cultura o espíritu de cuerpo que reprime y estigmatiza laboral y profesionalmente las conductas de filtración - leaking - o delación - whistle-blower - por parte de sus empleados y directivos ${ }^{46}$. En este sentido y tomando en cuenta lo anterior, se han desarrollado programas y sistemas de clemencia y delación compensada - leniency programs - orientados a empresas; estas iniciativas se originaron en Estados Unidos y, dada su eficacia, se han extendido a otras jurisdicciones nacionales.

\section{COMPRAS PÚBLICAS Y SUS MODALIDADES}

Las compras públicas son un factor modulador de la competencia en razón del cual los Estados actúan directamente en un mercado como promotor de pequeños y medianos empresarios, y como incentivo a la mejora en tecnología y productividad en el sector privado. De este modo, el Estado actúa como principal consumidor -oligopsonio-y en algunas ocasiones como único - monopsonio-, con el objetivo de suministrar a su institucionalidad los insumos y productos necesarios para el logro de sus fines. De tal manera, se logran propósitos como la estimulación de determinados sectores productivos asociados a pequeños empresarios, políticas de acción afirmativa y grupos en vulnerabilidad social ${ }^{47}$.

Entre las modalidades de contratación, la más común es la licitación pública, la cual se caracteriza por un proceso de formación

46 Ramírez-Duarte reconoce que la insuficiencia de material probatorio es una de las más importantes causas de las escasas decisiones sancionatorias en materia de colusión en la contratación pública en Colombia. Olga Lucía Ramírez-Duarte, Mecanismos para combatir la colusión en licitaciones: efectos de las decisiones sancionatorias sobre el proceso licitatorio en Colombia, 172 (Trabajo de investigación presentado como requisito para optar al título de magíster en derecho administrativo, Colegio Mayor de Nuestra Señora del Rosario, Facultad de Jurisprudencia, Bogotá, 2012). Disponible en: http://repository.urosario.edu.co/bitstream/handle/10336/3591/53166440-2012.pdf?sequence=1

47 Una enumeración doctrinal de sistemas de contratación pública es como sigue: procesos de contratación tradicional, procesos de contratación abreviados, procesos especiales de selección, convenio marco, compras corporativas y subasta inversa. En tal sentido, en Chile, la Ley 19886/2003, de Bases de Contratos Administrativos de Suministro y Prestación de Servicios, establece en su artículo 7 los tipos de licitaciones administrativas: licitación pública (procedimiento concursal de llamado público al mejor postor según las bases fijadas), licitación privada (procedimiento concursal de llamado a determinadas empresas seleccionadas a mejor postor según las bases fijadas). Chile, Ley 19886/2003, Ley de Bases de Contratos Administrativos de Suministro y Prestación de Servicios, 11 de julio de 2003. Disponible en: https://www.leychile.cl/Navegar?idNorma=213004 
del contrato presidido por una convocatoria a presentar ofertas o invitación en igualdad de oportunidades y un procedimiento público y transparente de selección de la mejor oferta para el interés público, a partir de bases y condiciones previamente establecidas por la entidad pública licitante ${ }^{48} 49$. Esta modalidad tiene por finalidad asegurar la mejor asignación posible de recursos públicos destinados a la contratación. Los elementos del proceso licitatorio, según la jurisprudencia del Consejo de Estado colombiano son: libre concurrencia de oferentes, igualdad de oferentes, sujeción del proceso licitatorio al pliego de condiciones, publicidad, transparencia y selección objetiva del mejor postor ${ }^{50}$. Teniendo en cuenta lo anterior, el pliego constituye la principal fuente de derechos y obligaciones de los sujetos de la licitación: la entidad pública licitante y sujetos postores u oferentes.

Otras modalidades son la licitación privada, más apropiada para la contratación de las empresas de economía mixta; la subasta inversa, que es un sistema de licitación por el cual se declara postor ganador al competidor que ofrezca el menor precio en un procedimiento de lanzamiento repetido de invitaciones a ofrecer por parte de la entidad pública licitante. Por su parte, la modalidad de acuerdo marco de precios consiste en un contrato suscrito entre la autoridad estatal de contratación pública y proveedores de tracto sucesivo, en el cual se acuerdan las condiciones y precio del suministro de determinados bienes o servicios por un plazo determinado. Esta forma de contratación se inserta en un proceso contractual en dos fases, la segunda de las cuales consiste en la fijación de las condiciones

48 Olga Lucía Ramírez-Duarte, Mecanismos para combatir la colusión en licitaciones: efectos de las decisiones sancionatorias sobre el proceso licitatorio en Colombia, 98 (Trabajo de investigación presentado como requisito para optar al título de magíster en derecho administrativo, Colegio Mayor de Nuestra Señora del Rosario, Facultad de Jurisprudencia, Bogotá, 2012). Disponible en: http:// repository.urosario.edu.co/bitstream/handle/10336/3591/53166440-2012.pdf?sequence=1

49 Reconocida en Colombia por el artículo 30 de la Ley 80 de 1993: "procedimiento mediante el cual la entidad estatal formula públicamente una convocatoria para que, en igualdad de oportunidades, los interesados presenten sus ofertas y seleccione entre ellas la más favorable". Colombia, Ley 80 de 1993, por la cual se expide el Estatuto General de la Administración Pública, 41.094 Diario Oficial, 28 de octubre de 1993. Disponible en: http://www.secretariasenado.gov.co/senado/basedoc/ ley_0080_1993.html

50 Olga Lucía Ramírez-Duarte, Mecanismos para combatir la colusión en licitaciones: efectos de las decisiones sancionatorias sobre el proceso licitatorio en Colombia, 100 (Trabajo de investigación presentado como requisito para optar al título de magíster en derecho administrativo, Colegio Mayor de Nuestra Señora del Rosario, Facultad de Jurisprudencia, Bogotá, 2012). 
específicas de suministro concreto de bienes al sector público, las cuales incluyen básicamente la cantidad y lugar de entrega ${ }^{51}$.

En China, la Ley de Invitación a Ofertas y Subastas Públicas, y la Ley de Compras Públicas establecen cinco modalidades: la invitación pública y la subasta por invitación, las más usadas; y otras tres de carácter especial: la negociación competitiva, la indagación por cuotas y las compras de única fuente ${ }^{52}$.

Todas las modalidades de contratación pública están sometidas a la vigencia de determinados principios. Para la región, el Sistema Económico Latinoamericano y del Caribe (SELA) ha erigido como tales el principio de competencia abierta y efectiva, que permite la asignación eficiente de recursos en la sociedad y el pleno acceso de las empresas a las compras públicas; y el principio de transparencia. Estos son el resultado de una tendencia global hacia la formulación y convergencia en torno a principios generales de procedimientos de compras públicas y han sido igualmente reconocidos por la Convención de Naciones Unidas contra la Corrupción en su artículo $9^{53}$.

51 Sobre esta modalidad, consúltense los documentos relativos al caso Evaristo Rafael RodríguezFelizzola vs. Agencia Nacional de Contratación Estatal - Colombia Compra Eficiente, sentencia CE SIII E 54549 de 2015. Colombia, Consejo de Estado, Sala de lo Contencioso Administrativo, Sección 3, Subsección C, Proceso 54549, consejero ponente Jaime Orlando Santofimio-Gamboa, 4 de septiembre de 2015. Disponible en: Disponible en: http://sintesis.colombiacompra.gov.co/sites/ default/files/sentencia/2015/CE\%20SIII\%20E\%2054549\%20DE\%202015/CE\%20SIII\%20E\%20 $54549 \% 20$ DE $\% 202015$ ORIGINAL.docx

52 La invitación pública está considerada como la modalidad básica — default method —, cuando no se aplican las restantes y consiste en la invitación pública a ofrecer con el objetivo de postular la mayor cantidad posible de postores. La subasta por invitación es utilizada para bienes y servicios con requerimientos especiales solo proveídos por determinados oferentes: consiste en enviar invitaciones a ofrecer solo a un determinado grupo de oferentes. La negociación competitiva, por su parte, se utiliza cuando una subasta ha quedado desierta al expirar el plazo de presentación de ofertas; en este caso, se envían invitaciones a un grupo aún más reducido y se establece un proceso de negociación privada con cada oferente que pueda presentarse. La indagación por cuotas consiste en la adquisición de bienes de caracteres homogéneos y estandarizados al postor que presente el precio más bajo. Por último, las compras de única fuente, como su nombre lo indica, son relevantes en situaciones de emergencia o cuando no existe un suministrador disponible. Sobre el tema, Ting Gong \& Na Zноч, Corruption and Marketization: Formal and Informal Rules in Chinese Public Procurement, 9 Regulation \& Governance, 1, 63-76 (2015).

53 Sistema Económico Latinoamericano y del Caribe, SELA, Las compras públicas como herramienta de desarrollo en América Latina y el Caribe, 29, Documento SP/RRSSCPALC/DT N²-15, Servicio Nacional de Contratación Pública del Ecuador, UNASUR, Redeplan (2015). Disponible en: http:// www.sela.org/media/268508/las-compras-publicas-como-herramienta-de-desarrollo-en-alc.pdf 


\section{DEFINICIÓN DE COLUSIÓN EN COMPRAS PÚBLICAS Y SUS MODALIDADES}

La colusión en compras públicas — bid rigging en derecho anglosajón- se define como las prácticas o acuerdos entre postores oferentes en un proceso de licitación convocado por una institución pública, encaminado a vulnerar el principio de competencia abierta y eficaz, en detrimento del interés patrimonial del Estado y en beneficio directo de los postores parte del acuerdo ${ }^{54}$. La determinación de colusión en compras públicas no es una tarea fácil; esto ha sido reconocido por varios autores ${ }^{55}$.

Las formas son de diversa índole y pueden manifestarse tanto en el proceso licitatorio como durante la ejecución del contrato público. En el primer caso, deben mencionarse las posturas encubiertas - cover bidding - , también conocidas como oferta de resguardo, oferta complementaria u oferta simbólica ${ }^{56}$. Se trata de un acuerdo encaminado a simular un escenario de subasta en licitación por medio de algunos de los siguientes fenómenos o conductas: presentación de una oferta más elevada o con condiciones leoninas o sin cumplir requerimientos legales, respecto del que ha sido designado para que gane la licitación; o posturas formuladas en términos por los cuales no tienen posibilidades reales de salir vencedoras. La

54 Entre los autores chilenos, Javier Tapia conceptualiza la Bid Rigging no como colusión en compras públicas, sino como presentación de ofertas conjuntas en subasta — collusive tendering-. JAVIER TAPIA, Carácter anticompetitivo de los acuerdos restrictivos de la competencia en el sector retail, 7 (2009).

55 Sirva de muestra la siguiente aclaración: "Sobre la conducta específica de colusión en licitaciones, es importante tener en cuenta que el límite entre lo permitido y lo prohibido es bastante indeterminado, pues muchas acciones desplegadas por los competidores, son consecuencia del funcionamiento del mercado. Así las cosas, si mi competidor sube precios o actúa de determinada manera dentro del mercado, yo debo tomar una reacción que en muchos casos será una conducta similar. En estos casos, no podemos hablar de una conducta prohibida y por ende, sancionable". Olga Lucía Ramírez-Duarte, Mecanismos para combatir la colusión en licitaciones: efectos de las decisiones sancionatorias sobre el proceso licitatorio en Colombia, 262 (Trabajo de investigación presentado como requisito para optar al título de magíster en derecho administrativo, Colegio Mayor de Nuestra Señora del Rosario, Facultad de Jurisprudencia, Bogotá, 2012).

56 En China se le conoce como peibiao. Otras de las prácticas de colusión en el mercado de compras públicas en China es el zizhi guakao, consistente en presentar oferta por interpósita persona, es decir, simular el sujeto postor. En esta modalidad, el sujeto que presenta la oferta y que no reúne los requisitos para presentarse, actúa en virtud de un acuerdo oculto con otra empresa que sí reúne tales requisitos y se presenta como postor en interés ajeno. TiNG Gong \& NA ZHou, Corruption and Marketization: Formal and Informal Rules in Chinese Public Procurement, 9 Regulation \& Governance, 1, 63-76, 71, 72 (2015). 
finalidad de las posturas encubiertas es simular una competencia ante el órgano convocante.

En segundo lugar, merece atención la supresión de ofertas - bid suppression-: conducta consistente en la presentación inicial de varias posturas y retiro sobrevenido de una o de un grupo de ofertas para allanar el camino al postor-ganador designado en el acuerdo colusorio. También se manifiesta como la presentación de una postura conjunta en una situación de probable y razonable presentación de postura simple. Este tipo de acuerdos pretende constituirse en un mecanismo de presión contra la entidad convocante, para aceptar la postura que queda después de la retirada del resto de las ofertas, a partir de la necesidad e interés de la administración en lograr la solución a los intereses públicos en juego.

En tercer lugar, clasifica como modalidad de colusión, la rotación de ofertas - bid rotation-: mecanismo colusorio compuesto en el cual se aplican sucesivamente varias posturas encubiertas, supresión de ofertas o asignación de mercados, con la particularidad de que en cada una de las modalidades sucesivas mencionadas, se rota la posición de postor-ganador. En este sentido, puede hablarse de rotación simple cuando se asignan las convocatorias en igual número para cada postor que participa en la colusión. En la rotación por ingreso, se asignan las convocatorias a ganar a cada postor según el principio de igualdad de ingresos para cada uno, de modo que la frecuencia de convocatorias ganadoras para cada uno puede variar según la cuantía que aporta cada licitación. En la rotación por entidad, la asignación del número de convocatorias por postor designado se realiza en función de la equidad de ingresos considerando las dimensiones de los postores parte del acuerdo.

Por último, la asignación de mercados - market allocation - es un acuerdo colusorio en el cual las partes se reparten el mercado de licitaciones públicas, con el propósito de disminuir los costos asociados a las operaciones. Esto significa que las partes del acuerdo colusorio acordarán asignarse las licitaciones públicas en razón de un criterio de cercanía geográfica entre instalaciones y logística del postor respecto del área a prestar el servicio o suministrar el producto. Con seguridad, esto implica una reducción considerable del costo operacional, por medio de la cercanía territorial y adicionalmente, por el efecto restrictivo de la competencia que se deriva de 
ese acuerdo. Las formas típicas en que se manifiesta esta modalidad son por medio de la abstención de producción o venta de productos distintos a los acordados en determinada zona o área geográfica $\mathrm{y}$ por medio de acuerdos de no ingresar en un nuevo mercado. También se manifiestan por medio de postores fantasmas, que son empresas que participan regularmente en procesos de licitación y nunca resultan vencedoras ni se les adjudica ningún contrato.

Las cuatro modalidades anteriores de colusión se manifiestan en el proceso licitatorio; sin embargo, durante la ejecución del contrato mismo pueden darse estas prácticas. De modo particular, el postor-ganador de la licitación puede ejecutar un acuerdo colusorio por medio de la subcontratación parcial o outsourcing hacia los postores perdedores, y por medio de una cesión parcial o total del contrato. De esta manera, la colusión continúa después de la adjudicación del contrato público y durante su ejecución, de modo que las empresas que forman parte del acuerdo colusorio se garantizan una participación por medio de la subcontratación.

\section{EVIDENCIA INDICIARIA Y CONDICIONES DE MERCADO FAVORABLES A LA COLUSIÓN}

Las prácticas y conductas colusorias, amén de difícil demostración, son deducibles a partir de determinados indicios en el comportamiento de las empresas y del mercado. Varios documentos y textos doctrinales se han dedicado a la enumeración de tales conductas, con el propósito de facilitar la investigación y determinación de estas prácticas. De ellos, resulta particularmente importante el documento An Antitrust Primer for Federal Prosecutors, del Departamento de Justicia de Estados Unidos, el cual ha servido de guía para la redacción de los Lineamientos de la Organización para la Cooperación y el Desarrollo Económicos y otros documentos de análoga importancia ${ }^{57}$.

Las evidencias indiciarias se clasifican en relación con las posturas, en relación con el precio o demás elementos de la oferta, y

57 Organización para la Cooperación y el Desarrollo Económicos, OCDE, Combate a la Colusión en los Procesos de Contratación Pública en México, Informe Analítico del Secretariado sobre el Cumplimiento de la Legislación, Regulaciones y Prácticas de la CFE con las Mejores Prácticas de la OCDE, 134 (2015). http://www.oecd.org/daf/competition/CombateColusi\%C3\%B3nContrataci $\% \mathrm{C} 3 \% \mathrm{~B} 3 \mathrm{nP} \% \mathrm{C} 3 \% \mathrm{BAblica}-\mathrm{M} \% \mathrm{C} 3 \% \mathrm{~A} 9 x$ ico-InformeCFE-2015.pdf 
en relación con la formalidad de la oferta. En el primer caso, los indicios de colusión en relación con las posturas son como siguen, y sin ánimo exhaustivo: la presencia de escasos oferentes cuando es razonable esperar un mayor número de posturas en licitación, la no presentación de un postor habitual, un récord o historial nulo de licitaciones ganadas por un postor, la presentación de una postura conjunta por medio de unión temporal de empresas o asociación ad hoc en circunstancias en que es posible y razonable esperar la presentación de posturas simples por cada empresa, recurrencia de una empresa ganadora en todas las licitaciones o en aquellas que responden a un patrón determinado de carácter geográfico, y la presentación de postura por empresa sin capacidad instalada para ejecutar el contrato público.

En el segundo caso, relativo a los indicios de colusión en relación con el precio o demás elementos del pliego, pueden manifestarse por medio de la presentación de varias ofertas cuyo precio se ubica ligeramente por encima del precio del eventual postor-ganador designado en el acuerdo colusorio, la presentación de posturas bajo términos y condiciones inaceptables por la entidad convocante, la repentina caída del precio ofertado al momento de entrar un nuevo postor en la convocatoria o una nueva empresa en el mercado, los movimientos bruscos y homogéneos de precios entre los competidores sin justificación en la estructura de costos, diferencias sustanciales entre precios ofertados para igual producto en distintas posturas, fijación colectiva por las empresas participantes de precios por encima del máximo declarado en la oferta, la dinámica líder-seguidor, entre otras.

Debe destacarse en particular un comportamiento dentro de la categoría de los indicios en relación con el precio o demás elementos de la oferta: es el intercambio de información entre postores. Esta conducta no constituye un indicio sino una prueba plena, en carácter de smoking-gun, dado que regularmente la ley establece en estos casos la presunción de colusión. En tercer lugar, deben mencionarse los indicios de colusión en relación con la formalidad de la oferta, las cuales aluden a la similitud no razonable en la papelería, tipografía, terminología u ortografía en la documentación presentada por varios postores. 
Amén de los indicios de colusión, debe mencionarse la existencia de condiciones de mercado favorables a esta práctica, la sola presencia de los mismos no constituye prueba plena de la existencia de una conducta colusoria, pero la concurrencia de varios indicios y condiciones de mercado da lugar a una razonable certeza o a razones fundadas para estimar la existencia de un acuerdo colusorio. Pueden mencionarse como condiciones de mercado favorables a la colusión, vinculadas a la situación de los postores-oferentes, las siguientes: elevadas barreras de entrada, escasos oferentes o situación consentida de monopolio, asociación institucionalizada con intensa actividad de los proveedores o activismo gremial, fácil constitución de uniones temporales de empresas, entre otras.

En relación con la situación de los compradores, se cuentan como condiciones de mercado favorables, la diversidad de oferentes y su fácil identificación. En relación con los productos, las condiciones de mercado que motivan o coadyuvan a los acuerdos colusorios son las ofertas públicas sobre commodities y la carencia o indisponibilidad de productos sustitutos. En relación con la situación del mercado, deben mencionarse la existencia de una demanda sostenida y sustancial, y una alta frecuencia de licitación, estabilidad y predictibilidad en el mercado. Por último, la práctica de subcontratación de proveedores que participaron en las posturas —además de ser indicio- es condición favorable a la colusión.

\section{RECONOCIMIENTO NORMATIVO Y CASUÍsTICA}

Una de las cuestiones asociadas al reconocimiento normativo de la colusión en compras públicas es la dualidad derecho de competencia y contratación pública. Esta no se manifiesta en el ámbito del análisis económico, pues hay una suerte de campo común que permite un enfoque integral del tema, no restringido a una sola disciplina. Amén de la dualidad mencionada, la colusión en las compras públicas ha sido tratada normativamente de dos maneras. Por un lado, algunos Estados la reconocen en la categoría más general de colusión (Estados Unidos, Reino Unido), mientras otros le 
conceden un tratamiento legislativo específico (Canadá, Noruega, Hungría $)^{58}$.

En el caso de Estados Unidos, estas prácticas encuentran represión legal en el derecho estatutario, en particular la Ley de Competencia en la Contratación - Competition in Contracting Act- ${ }^{59}$, así como en el Reglamento Federal de Adquisiciones - Federal Acquisition Regulation-. A pesar de tratarse de una economía de fuerte impronta liberal cuya legislación antitrust, en relación con la europea, puede ser la mayor de las veces deferente respecto de la concentración económica, no puede negarse la existencia en sus antecedentes de una etapa llamada estructural, en la cual el derecho de competencia incrementó su función moduladora de la actividad de la gran empresa ${ }^{60}$.

En el caso chino, como se dijo anteriormente, resulta un modelo a analizar. El gigante asiático inicia la dinámica reguladora Estado-

58 Organización para la Cooperación y el Desarrollo Económicos, OCDE, Combate a la Colusión en los Procesos de Contratación Pública en México, Informe Analítico del Secretariado sobre el Cumplimiento de la Legislación, Regulaciones y Prácticas de la CFE con las Mejores Prácticas de la OCDE, 25 (2015).

59 Estados Unidos, Public Law 98-369, 1984. Competition in Contracting Act, 18 de julio de 1984. Disponible en: https://www.gpo.gov/fdsys/granule/STATUTE-98/STATUTE-98-Pg494/contentdetail.html, https://www.gpo.gov/fdsys/pkg/STATUTE-98/pdf/STATUTE-98-Pg494.pdf

60 Baker da cuenta de tres etapas en el derecho de competencia de Estados Unidos: la etapa clásica, la etapa estructural y la etapa de la Escuela de Chicago. La etapa estructural, aquella de mayor grado de regulación y control del poder de mercado en Estados Unidos, coincidió con la recuperación económica posDepresión, a partir de 1938 junto a la acción del Comité Nacional Económico Temporal - Temporary National Economic Committee - y los esfuerzos de Thurman Arnold, Asistente Antimonopolio del Fiscal General. Estos esfuerzos en reforzar la regulación y el control comienzan a ver sus frutos en las decisiones US v. Socony-Vacuum Oil Co. (Estados Unidos, Suprema Corte, United States v. Socony-Vacuum Oil Co., 310 US 150, May 6, 1940), US v. Aluminium Co. of AmericaAlcoa (Estados Unidos, Corte de Apelaciones del 2 Circuito, United States v. Aluminium Co. of America, Alcoa, 148 F.2d 416, $2^{\text {nd }}$ Circ., March 12, 1945) y en las enmiendas Cellar-Kefauver a la Ley Clayton. Estados Unidos, Clayton Antitrust Act, 15 USC $\S \S 12-27,29$ USC $\S \S 52-53$. En cualquier caso, la esencia de la etapa estructural no consistió en la regulación y control sin más del poder de mercado, sino en un tácito entendimiento nacional - informal national understanding-, en un acuerdo producto de una negociación no explícita entre el Estado y su interés en la recuperación del poder de compra del consumidor y la gran empresa y su interés en la recuperación del margen de utilidades. El sentido de esta negociación determinó la liberación de la gran empresa de regulación jurídica pero manteniendo un control relativamente fuerte del poder de mercado y de vigilancia antimonopolio. Todo un quid pro quo: "El interés del consumidor hacia la izquierda ha favorecido un enfoque más intervencionista, redistributivo, regulatorio y de planificación nacional, mientras que el interés del productor hacia la derecha ha favorecido un enfoque menos intervencionista, de laissez-faire y autorregulatorio por la propia industria, tolerante de un mayor ejercicio del poder de mercado. Como producto de un acuerdo informal entre ambos intereses, se gestó un enfoque centrista que permitió a la economía lograr una mayor eficiencia que la que pudiera lograrse con alguno de los enfoques extremos". JONATHAN B. BAKER, Overlapping Financial Investor Ownership. Market Power and Antitrust Enforcement: My Qualified Agreement with Professor Elhauge, 129 Harvard Law Review Forum, 212-232 (2016). 
sector privado, a partir de las reformas económicas de los años 80 , caracterizadas por una primera etapa experimental, una segunda etapa de regulación puntual del experimento y una tercera etapa de generalización por medio de un marco normativo codificado y con propósito de estabilidad ${ }^{61}$.

En el ámbito latinoamericano, debe mencionarse el caso de México, donde la colusión en compras públicas es muy frecuente en el área de los medicamentos de uso hospitalario, al detectarse coordinación de posturas ante licitación por el Instituto Mexicano del Seguro Social, en el período 2002-2007. Para la determinación de tal conducta, se estableció como relevante un Mercado I (insulina) y un Mercado II (sueros y soluciones electrolíticas). En tal caso, los indicios de colusión fueron las comunicaciones entre los directivos de las empresas postoras en cantidad suficiente y coincidentes con los períodos de presentación de posturas, las reuniones entre directivos en la asociación gremial de empresas farmacéuticas, la coincidencia de ganadores, los altos márgenes de utilidad entre empresas farmacéuticas que admitían mejores posturas, entre otros. De igual forma, debe destacarse como indicio de importancia, la identificación de un período colusorio y un período competitivo en el comportamiento de los precios en postura ante la entrada de un nuevo competidor.

En Chile, la colusión está tipificada por el artículo 3 del Decreto Legislativo 211 de $1973^{62}$, mientras que el artículo 9 del texto refun-

61 La primera etapa experimental se desenvolvió básicamente en la década de los 80 , cuando inició el desarrollo de un sector privado proveedor de productos y servicios de diverso tipo, y de la administración pública requerida del uso eficiente de recursos financieros, por lo cual comienzan a darse las primeras experiencias de compras públicas en el sector de la construcción. Estas resultaron exitosas: reducción de tiempo y costos en los proyectos contratados, incremento en la transparencia y reducción de la discrecionalidad de los funcionarios locales para adjudicar proyectos. Como resultado de ello, a finales de los 80 , la fase experimental se había extendido a otros mercados de compras públicas como maquinaria, suministros médicos, proyectos de investigación científica y de infraestructura financiada con inversión extranjera. La segunda etapa se caracterizó por la regulación del experimento económico, por medio de normas sobre compras públicas. Las primeras reglas formales de corte local en este sentido fueron dictadas por la ciudad de Shenzhen, junto a regulaciones específicas del Ministerio de Finanzas. Por último, la tercera etapa inicia en el año 2000 con la promulgación de la Ley de Invitación a Ofertas y de Subasta Pública; y la adhesión a la Organización Mundial del Comercio, OMC, en 2001, y con ello, al Acuerdo de Compras Públicas, que exige la apertura del mercado de adquisiciones públicas a las empresas extranjeras. En razón de ello se dictó la Ley de Compras Públicas de 2003, sin derogar íntegramente la normativa anterior. Sobre la evolución, regulación, praxis y perspectivas de las compras públicas en China, TiNG Gong \& NA Zhou, Corruption and Marketization: Formal and Informal Rules in Chinese Public Procurement, 9 Regulation \& Governance, 1, 63-76, 66 (2015).

62 Chile, Decreto Legislativo 211 de 1973, Ley de Defensa de la Libre Competencia, Refundido, 18 
dido de la 18575 o Ley Orgánica Constitucional de Bases Generales de la Administración del Estado ${ }^{63}$, dispone que la contratación pública se realizará por medio de licitación. En este sentido, conforme el Decreto Legislativo 211 de 1973, las atribuciones de la Fiscalía Nacional Económica en materia de colusión son: acceso y allanamiento a recintos empresariales, incautación de documentación potencialmente útil para la investigación, vigilancia en las comunicaciones, consulta de registros de comunicaciones de empresas en investigación, entre otras.

En el caso colombiano, la consagración normativa de las prácticas restrictivas de la competencia y en particular de la colusión, encuentra mayor dispersión. Así deben mencionarse la Ley 155/195964; Ley 1340/200965; el artículo 47, numeral 9 del Decreto 2153/1992 ${ }^{66}$, a partir de la cláusula general del artículo 1 de la Ley 155/1959; Decreto 2153/1992, derogado en parte, Decreto 3523/200967 modificado por el derogado Decreto 1687/2010 ${ }^{68} 69$. Esta dispersión también se refleja en las competencias y atribuciones de la Superintendencia de Industria y Comercio: el artículo 6 de la Ley 1340/2009 establece la competencia general exclusiva de la Superintendencia de Industria

de octubre de 2004. Disponible en: https://www.leychile.cl/Navegar?idNorma=5872, https://www. leychile.cl/Navegar?idNorma $=236106 \&$ idVersion $=$

63 Chile, Ley 18575 de 1986, Ley Orgánica Constitucional de Bases Generales de la Administración del Estado de Chile, 12 de noviembre de 1986. Disponible en: https://www.leychile.cl/ Navegar?idNorma=29967, texto refundido en: https://www.leychile.cl/Navegar?idNorma=191865 \&idVersion $=$

64 Colombia, Ley 155 de 1959, por la cual se dictan algunas disposiciones sobre prácticas comerciales restrictivas, 30.138 Diario Oficial, 22 de enero de 1960. Disponible en: http://www.alcaldiabogota. gov.co/sisjur/normas/Norma1.jsp?i=38169

65 Colombia, Ley 1340 de 2009, por medio de la cual se dictan normas en materia de protección de la competencia, 47.420 Diario Oficial, 24 de julio de 2009. Disponible en: http://www.secretariasenado. gov.co/senado/basedoc/ley_1340_2009.html

66 Colombia, Decreto 2153 de 1992, por el cual se reestructura la Superintendencia de Industria y Comercio y se dictan otras disposiciones, 40.704 Diario Oficial, 31 de diciembre de 1992. Disponible en: http://www.secretariasenado.gov.co/senado/basedoc/decreto_2153_1992.html

67 Colombia, Decreto 3523 de 2009, por el cual se modifica la estructura de la Superintendencia de Industria y Comercio y se determinan las funciones de sus dependencias, 47.473 Diario Oficial, 15 de septiembre de 2009. Disponible en: https://www.cancilleria.gov.co/sites/default/files/Normograma/ docs/decreto 3523 2009.htm

68 Colombia, Decreto 1687 de 2010, por el cual se modifica el Decreto 3523 de 2009, 47.709 Diario Oficial, 14 de mayo de 2010. Disponible en: http://www.secretariasenado.gov.co/senado/basedoc/ decreto_1687_2010.html

69 Artículo 47, numeral 9, Decreto 2153/1992: "Para el cumplimiento de las funciones a que se refiere el artículo 44 del presente decreto se consideran contrarios a la libre competencia, entre otros, los siguientes acuerdos: [...] Los que tengan por objeto la colusión en las licitaciones o concursos o los que tengan como efecto la distribución de adjudicaciones de contratos, distribución de concursos o fijación de términos de las propuestas". 
y Comercio, SIC, para investigar y perseguir la colusión, mientras que los artículos 44 y 47 del Decreto 2153/1992 aluden igualmente a esta práctica restrictiva de la competencia. Entre las formas de colusión reconocidas en la norma colombiana, encontramos la colusión en licitaciones, colusión en concursos, efecto distribuidor de adjudicaciones de contratos, efecto distribuidor de concursos y el efecto de fijación de términos de propuestas.

De la misma manera, la colusión es un tema de importante tratamiento por la jurisprudencia constitucional. Ramírez-Duarte menciona como relevante la sentencia C-415/1994, magistrado ponente Eduardo Cifuentes-Muñoz, la cual sostiene que la intención del legislador en materia de represión de la colusión en las compras públicas es la promoción de "condiciones más favorables y provechosas para el interés público", "asegurar igualdad de oportunidades entre los particulares para contratar con el Estado" y "una activa y honesta competencia". De esta manera, la jurisprudencia constitucional colombiana reconoce el "mercado honesto" y la igualdad de oportunidades para los empresarios, y reconoce, para el ámbito público, como valor adicional: el interés social representado en el Estado como comprador en el mercado ${ }^{70}$.

La autoridad en derecho de competencia en Colombia ha establecido en al menos una ocasión, un criterio de colusión encaminado no solo a la represión por los efectos, sino además, por la mera probabilidad de su alcance. En este sentido, la autoridad ha determinado que existe colusión con el mero hecho de que se persiga incrementar la probabilidad de adjudicación ${ }^{71}$.

Del mismo modo, la autoridad colombiana en derecho de competencia ha sido enfática al declarar la "extraña coincidencia" de

70 Olga Lucía Ramírez-Duarte, Mecanismos para combatir la colusión en licitaciones: efectos de las decisiones sancionatorias sobre el proceso licitatorio en Colombia (Trabajo de investigación presentado como requisito para optar al título de magíster en derecho administrativo, Colegio Mayor de Nuestra Señora del Rosario, Facultad de Jurisprudencia, Bogotá, 2012).

71 "Resulta necesario indicar, que el hecho de que el mecanismo colusorio adoptado por los investigados, no fuera especialmente eficaz para obtener la adjudicación de los contratos, no permite prescindir del reproche, mucho menos cuando los investigados declararon expresamente el objeto perseguido, cuál era el de coludir en los procesos de contratación en los que participaron, absteniéndose de competir entre ellos en la instancia previa a la evaluación de las propuestas con el compromiso de subcontratar posteriormente entre ellos". Colombia, Superintendencia de Industria y Comercio, Resolución 1055 de 2009, Caso Intersystem, Buitrago Camargo y Vega Cruz, 19 de enero de 2009. Disponible en: http://www.sic.gov.co/recursos_user/documentos/normatividad/ Publicaciones_Despacho_3/sicdecisiones2/RESOLUCIONES_COMPETENCIA_ANOS/2009/ RESOLUCION_̄1055_DE_19_DE_ENERO_DE_2009_SANCIŌN_INTERSYSTEM.pdf 
precios entre postores en licitación, como conducta colusoria. En este sentido, se investigan las posturas con precio irrisorio, irracionalmente bajos para el giro de comercio y que necesariamente implican operaciones a pérdidas para el postor ${ }^{72}$. Esta práctica de ofertar con precios irrisorios se hace con el objetivo de defraudar el procedimiento de selección objetiva de la mejor oferta.

En Ecuador, la colusión en compras públicas se considera una práctica prohibida expresamente por el artículo 11, numerales 6 (para la colusión horizontal) y 21 (para la colusión vertical) de la Ley Orgánica de Regulación y Control del Poder de Mercado ${ }^{73}$. Asimismo, el artículo 8.4 del Reglamento de la Ley Orgánica ${ }^{74}$ dispone la presunción de práctica restrictiva vinculada a las compras públicas junto al artículo 41 que establece a la Superintendencia de Control del Poder de Mercado, SCPM, la obligación de implementar mecanismos de vigilancia y monitoreo de los procesos de contratación pública ${ }^{75}$.

72 Sobre el tema, es necesario considerar lo siguiente: "Teniendo en cuenta las reglas previamente establecidas en el Pliego de Condiciones, así como los resultados históricos de licitaciones anteriores con mecanismos de asignación de puntaje similares al de este proceso, es posible concluir que para tener una oferta competitiva en el mismo, es decir, una oferta con posibilidades de ser adjudicatario, los precios ofrecidos debían situarse un rango de valores cercano al 99\% de los precios oficiales". Olga Lucía Ramírez-Duarte, Mecanismos para combatir la colusión en licitaciones: efectos de las decisiones sancionatorias sobre el proceso licitatorio en Colombia, 110 (Trabajo de investigación presentado como requisito para optar al título de magíster en derecho administrativo, Colegio Mayor de Nuestra Señora del Rosario, Facultad de Jurisprudencia, Bogotá, 2012).

73 Ecuador, Ley s/n de 2011, Ley Orgánica de Regulación y Control del Poder de Mercado, 555 Registro Oficial, 13 de octubre de 2011. Disponible en: http://www.planificacion.gob.ec/wp-content/uploads/ downloads/2012/10/Ley-Organica.pdf

74 Ecuador, Decreto Ejecutivo 1152 de 2012 [Presidencia de la República del Ecuador], Reglamento de la Ley Orgánica de Regulación y Control del Poder de Mercado, 697 Registro Oficial, 7 de mayo de 2012. Disponible en: http://www.scpm.gob.ec/wp-content/uploads/2015/03/REGLAMENTO-ALA-LEY-ORGA $\%$ C2\%A6\%C3\%BCNICA-DE-REGULACIO $\% \mathrm{C} 2 \% \mathrm{~A} 6 \% \mathrm{C} 3 \% \mathrm{BCN}-\mathrm{Y}-\mathrm{CONTROL}$ DEL-PODER-DE-MERCADO.pdf

75 Adicionalmente, en Ecuador están vigentes otras disposiciones normativas que prohíben la colusión en las compras públicas: Ley Orgánica del Sistema Nacional de Contratación Pública (artículos 1, 4, 5, 6.5, 9, 10, 14, 15, 25.1 25.2, 27, 29, Ecuador, Ley s/n de 2008, Ley Orgánica del Sistema Nacional de Contratación Pública de la República del Ecuador, 395 Registro Oficial, 4 de agosto de 2008). Ley Orgánica de la Función de Transparencia y Control Social (artículos 3.3, 3.5, 3.7, 4.1, 4.3, 4.4, 7.1, 7.3, Ecuador, Ley s/n de 2013, Ley Orgánica de la Función de Transparencia y Control Social de la República del Ecuador, 53 Registro Oficial, Suplemento, 7 de agosto de 2013); Ley Orgánica de la Contraloría General del Estado (artículos 1, 2, 33 y 54, Ecuador, Ley 73 de 2002, Ley Orgánica de la Contraloría General del Estado, 595 Registro Oficial, 12 de junio de 2002); Ley Orgánica de la Procuraduría General del Estado (artículos 3, e, g, 5, g, Ecuador, Ley s/n de 2004, Ley Orgánica de la Procuraduría General del Estado de la República del Ecuador, 312 Registro Oficial, 13 de abril de 2004); Decisión 668 CAN, Plan Andino de Lucha contra la Corrupción (Comunidad Andina, CAN, Consejo Andino de Ministros de Relaciones Exteriores, 18 Reunión, Decisión 668, Plan Andino de Lucha contra la Corrupción, 13 de junio de 2007). 


\section{CONCLUSIONES}

A modo de conclusión, la presente contribución pretende destacar un aspecto de importante vocación técnica en el derecho de competencia, pero que no por ello está al margen del proceso democrático en un país. En Estados Unidos, el derecho de competencia aún tiene un fuerte componente político, junto al inevitable e indispensable contenido de análisis económico y técnico; la relación entre legislador, autoridades de cumplimiento de la legislación antitrust, sistema judicial y empresa privada ha discurrido en términos de acción legislativa, búsqueda empresarial de subterfugios legales y corrección interpretativa de las lagunas expuestas por el legislador, lo cual se ha manifestado desde etapa temprana como la decisión E. C. Knight, de la Corte Suprema ${ }^{76}$, que en 1895 abrió un escape a fusiones y consolidaciones empresariales y que concluye parcialmente en los casos Addyston Pipe \& Steel Co. V. US ${ }^{77}$, y Northern Securities Co. V. US ${ }^{78}$.

Para Latinoamérica, debe añadirse que el derecho de competencia es un ámbito normativo relativamente nuevo, pero sobre todo indiferente. La mayoría de las veces, a la comunidad profesional del derecho en la región le es indiferente el control del poder de mercado y su funcionamiento eficiente por un sinnúmero de razones. Entre ellas pueden mencionarse la concentración de la titularidad de las empresas en grupos familiares cerrados, a diferencia de Estados Unidos o Europa, donde, sin negar la existencia de tales grupos, la titularidad de las empresas está más diversificada entre inversionistas institucionales o personales, gracias a un fuerte desarrollo del mercado de valores.

Otra de las razones es el poco ímpetu del emprendimiento empresarial serio, que impide la creación de una comunidad emprendedora vigilante de prácticas anticompetitivas por parte de las empresas grandes y establecidas, a diferencia de Estados Unidos y

76 Estados Unidos, Suprema Corte, United States v. E. C. Knight Co., 156 US 1 (January 21, 1895). Disponible en: https://supreme.justia.com/cases/federal/us/156/1/case.html

77 Estados Unidos, Suprema Corte, Addyston Pipe \& Steel Co. v. United States, 175 US 211 (December 4, 1899). Disponible en: https://supreme.justia.com/cases/federal/us/175/211/case.html, https://www. law.cornell.edu/supremecourt/text/175/211

78 Estados Unidos, Suprema Corte, Northern Securities Co. v. United States, 193 US 197 (March 14, 1904). Disponible en: https://www.law.cornell.edu/supremecourt/text/193/197 
Europa, donde existe una vasta comunidad empresarial interesada en el funcionamiento competitivo de los mercados. Por último, en Estados Unidos y Europa, la vigilancia del mercado no depende únicamente del Estado, sino de múltiples organizaciones, observatorios e instancias ciudadanas interesadas en el bienestar del consumidor. En el caso latinoamericano, el interés por el consumidor solo parte del propio Estado, sea por una actitud paternalista de este o una actitud del propio consumidor, siempre a la expectativa de la responsabilidad estatal en su bienestar. De algún modo, el principio de subsidiariedad no es muy fértil en la región.

Por último, entre los factores mencionados, cabe destacar la carencia de una masa crítica de profesionales expertos que permita formar una comunidad académica y de litigantes que hagan funcionales la también escasa y novísima institucionalidad encargada de la vigilancia y control del mercado, y de las prácticas ya expuestas.

Acorde con lo anterior, deben definirse dos tipos de soluciones al problema del derecho de competencia en general y de la colusión en compras públicas en particular: las de carácter legal y las de carácter integral. En el primer tipo de soluciones deben considerarse la solicitud de una fuerte asistencia de organismos internacionales para reinventar y reconfigurar la norma antimonopolio, la formación de expertos y litigantes en la materia, la promoción de la investigación y publicaciones con criterio interdisciplinar de análisis económico y legal del tema. No obstante, la eficacia de las anteriores medidas radica en la adopción del segundo tipo de soluciones, las de carácter integral.

Este último tipo de soluciones deben considerar políticas de Estado encaminadas a lograr en lo posible el consenso entre gran empresa, sectores laborales y Estado en torno al funcionamiento competitivo del mercado. En cualquier caso, la colusión en compras públicas no es un asunto solo del derecho de competencia, sino que debe formar parte de la agenda anticorrupción en toda sociedad moderna; en razón de ello, y desde una perspectiva legal, la definición legislativa de limitaciones, exenciones, modalidades, alcance y límites, evidencia indiciaria, condiciones favorables y el seguimiento casuístico resultan indispensables para la eficacia de este punto en la agenda anticorrupción. 


\section{BIBLIOGRAFÍA}

\section{Libros}

Elhauge, Einer \& Geradin, Damien, Global Antitrust Law and Economics (Foundation Press, Thomson Reuters, New York, 2011).

Weishaar, Stefan E., Cartels, Competition and Public Procurement. Law and Economics Approaches to Bid Rigging (Edward Elgar Publishing, Cheltenham, 2013).

Witker, Jorge, Derecho de la competencia en América, Canadá, Chile, Estados Unidos y México (Fondo de Cultura Económica, FCE, 2000).

\section{Revistas}

Álvarez-Londoño, Luis Fernando, S.J., Últimas tendencias en derecho de la competencia en América Latina, 115 Vniversitas, 247-262 (2008). Disponible en: http://revistas. javeriana.edu.co/index.php/vnijuri/article/view/14584/11766

Baker, Jonathan B., Competition Policy as a Political Bargain, 73 Antitrust Law Journal, 2, 483-530 (2006). Disponible en: https://papers.ssrn.com/sol3/papers. cfm?abstract_id $=649442$

Baker, Jonathan B., Overlapping Financial Investor Ownership. Market Power and Antitrust Enforcement: My Qualified Agreement with Professor Elhauge, 129 Harvard Law Review Forum, 212-232 (2016). Disponible en: https:// harvardlawreview.org/2016/03/overlapping-financial-investor-ownership-marketpower-and-antitrust-enforcement-my-qualified-agreement-with-professorelhauge/

Coase, Ronald, The Nature of the Firm, 4 Economica. Blackwell Publishing, 16, 386405 (1937). doi:10.1111/j.1468-0335.1937.tb00002.x. Disponible en: http://www. colorado.edu/ibs/es/alston/econ4504/readings/The $\% 20$ Nature $\% 20$ of $\% 20$ the $\% 20$ Firm $\% 20$ by $\% 20$ Coase.pdf

Datta, Devangshu, Investing in Peer Stocks, Business Standard News (August $2^{\text {nd }}, 2015$ ). Disponible en: http://www.business-standard.com/article/pf/investing-in-peerstocks-115080200784_1.html

Elhauge, Einer, Horizontal Shareholding, 129 Harvard Law Review, 1267-1317 (2016). Disponible en: https://harvardlawreview.org/2016/03/horizontal-shareholding/

Gong, Ting \& Zhou, Na, Corruption and Marketization: Formal and Informal Rules in Chinese Public Procurement, 9 Regulation \& Governance, 1, 63-76 (2015). Disponible en: https://www.researchgate.net/publication/261141803_Corruption_ and_marketization_Formal_and_informal_rules_in_Chinese_public_ procurement

Kovacic, William \& Shapiro, Carl, Antitrust Policy: A Century of Economic and Legal Thinking, 14 Journal of Economic Perspectives, 1, $43-60$ (2000). Disponible en: http://faculty.haas.berkeley.edu/shapiro/century.pdf

Lianos, IoAnnis, Collusion in Vertical Relations under Article 81 EC, 45 Common Market 
Law Review, 4, 1027-1077 (2008). Disponible en: https://papers.ssrn.com/sol3/ papers.cfm?abstract_id=1089681\&rec $=1 \&$ srcabs $=1724891 \&$ alg $=1 \&$ pos $=1$

\section{Working papers}

Kaplow, Louis \& Shapiro, Carl, Antitrust (John M. Olin Center for Law, Economics and Business, Harvard Law School Discussion Paper 01/2007, 2007). Disponible en: http://www.law.harvard.edu/programs/olin_center/papers/pdf/Kaplow_ Shapiro_575.pdf

Kaplow, Louis \& Shapiro, Carl, Market Definition and the Merger Guidelines Antitrust (John M. Olin Center for Law, Economics and Business, Harvard Law School Discussion Paper No. 695 05/2011, 2011). Disponible en: http://www.law.harvard. edu/programs/olin_center/papers/pdf/Kaplow_695.pdf

Salop, Steven \& O’Brien, Daniel, Competitive Effect of Partial Ownership: Financial Interest and Corporate Control, 67 Antitrust Law Journal, 559-614 (2000). Disponible en: http://scholarship.law.georgetown.edu/cgi/viewcontent. cgi? article $=1200 \&$ context $=$ facpub

Volosin, Natalia, Datos abiertos, corrupción y compras públicas (Iniciativa Latinoamericana por los Datos Abiertos, ILDA, OpenData, Working Paper, 2015). Disponible en: http://idatosabiertos.org/wp-content/uploads/2015/10/5.Corrupcion-y-compras-publicas-Volosin1.pdf

\section{Informes, reportes, documentos}

Estados Unidos, Department of Justice, Antitrust Division, An Antitrust Primer for Federal Prosecutors (Department of Justice, Washington, 1994, 2005). Disponible en: https://www.justice.gov/atr/antitrust-primer-federal-law-enforcementpersonnel-revised-april-2005

Organización para la Cooperación y el Desarrollo Económicos, OCDE, Combate a la Colusión en los Procesos de Contratación Pública en México, Informe Analítico del Secretariado sobre el Marco Jurídico y las Prácticas de Contratación Pública en el Estado de México (2012). http://www.oecd.org/daf/competition/ GEM_Report_2012_Spanish.pdf

Organización para la Cooperación y el Desarrollo Económicos, OCDE, Combate a la Colusión en los Procesos de Contratación Pública en México, Informe Analítico del Secretariado sobre el Cumplimiento de la Legislación, Regulaciones y Prácticas de la CFE con las Mejores Prácticas de la OCDE (2015). http://www. oecd.org/daf/competition/CombateColusi $\% \mathrm{C} 3 \% \mathrm{~B} 3 \mathrm{nContrataci} \% \mathrm{C} 3 \% \mathrm{~B} 3 \mathrm{nP} \% \mathrm{C}$ 3\%BAblica-M $\%$ C3\%A9xico-InformeCFE-2015.pdf

Sistema Económico Latinoamericano y del Caribe, SELA, Las compras públicas como herramienta de desarrollo en América Latina y el Caribe, Documento SP/RRSSCPALC/DT N²-15, Servicio Nacional de Contratación Pública del Ecuador, UNASUR, Redeplan (2015). Disponible en: http://www.sela.org/ media/268508/las-compras-publicas-como-herramienta-de-desarrollo-en-alc. pdf 


\section{Tesis}

Ramírez-Duarte, Olga Lucía, Mecanismos para combatir la colusión en licitaciones: efectos de las decisiones sancionatorias sobre el proceso licitatorio en Colombia (Trabajo de investigación presentado como requisito para optar al título de magíster en derecho administrativo, Colegio Mayor de Nuestra Señora del Rosario, Facultad de Jurisprudencia, Bogotá, 2012). Disponible en: http:// repository.urosario.edu.co/bitstream/handle/10336/3591/53166440-2012. pdf?sequence $=1$

\section{Publicaciones web}

Davidson, Ken, Elhauge, Read the Wrong Way? (9 de agosto de 2015). https://www. linkedin.com/pulse/elhauge-read-wrong-way-ken-davidson

TAPIA, JAVIER, Carácter anticompetitivo de los acuerdos restrictivos de la competencia en el sector retail (2009). Disponible en: http://papers.ssrn.com/sol3/papers. cfm?abstract_id=1440695

\section{Tratados internacionales}

Comunidad Económica Europea, Tratado Constitutivo de la Comunidad Económica Europea o Tratado CEE, Roma, 25 de marzo de 1957. Disponible en: http:// ocw.uc3m.es/historia-del-derecho/historia-de-la-integracion-europea/tratados/ Tratado_Cee.pdf/view, https://www.boe.es/legislacion/enlaces/documentos/ue/ Trat_EC_consol.pdf

Unión Europea, Tratado de la Unión Europea y Tratado de Funcionamiento de la Unión Europea [TFUE], 326 Diario Oficial, 26 de octubre de 2012. Disponible en: http://eur-lex.europa.eu/legal-content/ES/TXT/?uri=celex\%3A12012E\%2FTXT

Unión Europea, Tratado de Lisboa por el que se modifican el Tratado de la Unión Europea y el Tratado constitutivo de la Comunidad Europea [Tratado UE], 306 Diario Oficial de la Unión Europea, 17 de diciembre de 2007. Disponible en: http:// eur-lex.europa.eu/legal-content/ES/TXT/?uri=CELEX\%3A12007L\%2FTXT

\section{Legislación internacional}

Chile, Decreto Legislativo 211 de 1973, Ley de Defensa de la Libre Competencia, Refundido, 18 de octubre de 2004. Disponible en: https://www.leychile.cl/ Navegar?idNorma=5872, https://www.leychile.cl/Navegar?idNorma=236106\& idVersion=

Chile, Ley 18575 de 1986, Ley Orgánica Constitucional de Bases Generales de la Administración del Estado de Chile, 12 de noviembre de 1986. Disponible en: https://www.leychile.cl/Navegar?idNorma=29967, texto refundido en: https:// www.leychile.cl/Navegar?idNorma=191865\&idVersion=

Chile, Ley 19886/2003, Ley de Bases de Contratos Administrativos de Suministro y 
Prestación de Servicios, 11 de julio de 2003. Disponible en: https://www.leychile. $\mathrm{cl} /$ Navegar?idNorma $=213004$

Colombia, Decreto 2153 de 1992, por el cual se reestructura la Superintendencia de Industria y Comercio y se dictan otras disposiciones, 40.704 Diario Oficial, 31 de diciembre de 1992. Disponible en: http://www.secretariasenado.gov.co/senado/ basedoc/decreto_2153_1992.html

Colombia, Decreto 3523 de 2009, por el cual se modifica la estructura de la Superintendencia de Industria y Comercio y se determinan las funciones de sus dependencias, 47.473 Diario Oficial, 15 de septiembre de 2009. Disponible en: https://www.cancilleria.gov.co/sites/default/files/Normograma/docs/ decreto_3523_2009.htm

Colombia, Decreto 1687 de 2010, por el cual se modifica el Decreto 3523 de 2009, 47.709 Diario Oficial, 14 de mayo de 2010. Disponible en: http://www.secretariasenado. gov.co/senado/basedoc/decreto_1687_2010.html

Colombia, Ley 155 de 1959, por la cual se dictan algunas disposiciones sobre prácticas comerciales restrictivas, 30.138 Diario Oficial, 22 de enero de 1960. Disponible en: http://www.alcaldiabogota.gov.co/sisjur/normas/Norma1.jsp?i=38169

Colombia, Ley 80 de 1993, por la cual se expide el Estatuto General de la Administración Pública, 41.094 Diario Oficial, 28 de octubre de 1993. Disponible en: http://www. secretariasenado.gov.co/senado/basedoc/ley_0080_1993.html

Colombia, Ley 1340 de 2009, por medio de la cual se dictan normas en materia de protección de la competencia, 47.420 Diario Oficial, 24 de julio de 2009. Disponible en: http://www.secretariasenado.gov.co/senado/basedoc/ley_1340_2009.html

Comunidad Andina, CAN, Consejo Andino de Ministros de Relaciones Exteriores, $18^{\mathrm{a}}$ Reunión, Decisión 668, Plan Andino de Lucha contra la Corrupción, 13 de junio de 2007. Disponible en: http://www.sice.oas.org/trade/JUNAC/Decisiones/ DEC668s.doc

Comunidad Económica Europea, Reglamento 17 de 1962, Normas de aplicación y de procedimiento de los artículos 81 y 82 del Tratado CE, 013 Diario Oficial, 21 de febrero de 1962. Disponible en: http://eur-lex.europa.eu/legal-content/ES/ $\mathrm{TXT} /$ ?uri=uriserv $\% 3 \mathrm{~A} 126042$

Comunidad Económica Europea, Reglamento (CEE) 4064 de 1989 del Consejo, sobre el control de operaciones de concentración de empresas, 395 Diario Oficial de las Comunidades Europeas, 30 de diciembre de 1989. Disponible en: http://eurlex.europa.eu/legal-content/ES/TXT/PDF/?uri=CELEX:31989R4064\&from=ES

Ecuador, Decreto Ejecutivo 1152 de 2012 [Presidencia de la República del Ecuador], Reglamento de la Ley Orgánica de Regulación y Control del Poder de Mercado, 697 Registro Oficial, 7 de mayo de 2012. Disponible en: http://www. scpm.gob.ec/wp-content/uploads/2015/03/REGLAMENTO-A-LA-LEYORGA $\%$ C $2 \%$ A6 $\%$ C3 $\%$ BCNICA-DE-REGULACIO $\%$ C2 $\%$ A $6 \% \mathrm{C} 3 \% \mathrm{BCN}-\mathrm{Y}-$ CONTROL-DEL-PODER-DE-MERCADO.pdf

Ecuador, Ley 73 de 2002, Ley Orgánica de la Contraloría General del Estado, 595 Registro Oficial, 12 de junio de 2002. Disponible en: http://www.espol.edu.ec/ sites/default/files/archivos_transparencia/LEY\%20organica $\% 20 \mathrm{de} \% 201 \mathrm{a} \% 20$ contraloria $\% 20$ general $\% 20$ del $\% 20$ estado.pdf 
Ecuador, Ley s/n de 2004, Ley Orgánica de la Procuraduría General del Estado de la República del Ecuador, 312 Registro Oficial, 13 de abril de 2004. Disponible en: http://www.desarrolloamazonico.gob.ec/wp-content/uploads/ downloads/2014/05/LEY-ORGANICA-DE-LA-PROCURADURIAGENERAL-DEL-ESTADO-act.pdf

Ecuador, Ley s/n de 2008, Ley Orgánica del Sistema Nacional de Contratación Pública de la República del Ecuador, 395 Registro Oficial, 4 de agosto de 2008. Disponible en: http://www.justicia.gob.ec/wp-content/uploads/2015/05/LEY-ORGANICADEL-SISTEMA-NACIONAL-DE-CONTRATACION-PUBLICA.pdf

Ecuador, Ley s/n de 2011, Ley Orgánica de Regulación y Control del Poder de Mercado, 555 Registro Oficial, 13 de octubre de 2011. Disponible en: http://www. planificacion.gob.ec/wp-content/uploads/downloads/2012/10/Ley-Organica.pdf

Ecuador, Ley s/n de 2013, Ley Orgánica de la Función de Transparencia y Control Social de la República del Ecuador, 53 Registro Oficial, Suplemento, 7 de agosto de 2013. Disponible en: https://www.quito-turismo.gob.ec/descargas/JUNIO/baselegal/ LOTAIP.pdf, http://www.ftcs.gob.ec/images/docs/2015/proyecto_ley_organica. pdf

España, Ley 15 de 2007, de Defensa de la Competencia, 159 Boletín Oficial del Estado, $B O E, 4$ de julio de 2007. Disponible en: https://www.boe.es/buscar/doc. php?id=BOE-A-2007-12946

Estados Unidos, Clayton Antitrust Act, 15 USC §§ 12-27, 29 USC §§ 52-53. Disponible en: http://gwclc.com/Library/America/USA/The\%20Clayton\%20Act.pdf

Estados Unidos, Federal Acquisition Regulation, 48 CFR 1. Disponible en: https:// www.acquisition.gov/?q=browsefar, https://www.gpo.gov/fdsys/pkg/CFR-2011title48-vo12/pdf/CFR-2011-title48-vol2-chap1.pdf

Estados Unidos, Public Law 98-369, 1984. Competition in Contracting Act, 18 de julio de 1984. Disponible en: https://www.gpo.gov/fdsys/granule/STATUTE-98/ STATUTE-98-Pg494/content-detail.html, https://www.gpo.gov/fdsys/pkg/ STATUTE-98/pdf/STATUTE-98-Pg494.pdf

Estados Unidos, Public Law 98-544, Local Government Antitrust Act, 24 de octubre de 1984. Disponible en: https://www.gpo.gov/fdsys/pkg/STATUTE-98/pdf/ STATUTE-98-Pg2750.pdf

Estados Unidos, Public Law 114-38, 15 USC chapter 1-7, 28 de julio de 2015. Disponible en: https://www.congress.gov/114/plaws/publ38/PLAW-114publ38.pdf

México, Ley Federal de Competencia Económica, Diario Oficial de la Federación, 24 de diciembre de 1992. Disponible en: http://www.diputados.gob.mx/LeyesBiblio/ abro/lfce/LFCE_abro.pdf

México, Ley Federal de Competencia Económica, Diario Oficial de la Federación, 23 de mayo de 2014. Disponible en: http://www.diputados.gob.mx/LeyesBiblio/pdf/ LFCE_270117.pdf

Organización Mundial de la Propiedad Intelectual, OMPI, Disposiciones tipo sobre la protección contra la competencia desleal (Ginebra, OMPI, 1996). http://www.wipo. int/edocs/pubdocs/es/intproperty/832/wipo_pub_832.pdf

Organización Mundial del Comercio, OMC, Acuerdo revisado sobre contratación 
pública, anexo al Protocolo por el que se modifica el Acuerdo sobre contratación pública, 30 de marzo de 2012. Disponible en: https://www.wto.org/spanish/ docs_s/legal_s/rev-gpr-94_01_s.pdf

Unión Europea, Reglamento (CE) 1 de 2003 del Consejo, relativo a la aplicación de las normas sobre competencia previstas en los artículos 81 y 82 del Tratado, 001 Diario Oficial, 4 de enero de 2003. Disponible en: http://eur-lex.europa.eu/legalcontent/ES/ALL/?uri=celex:32003R0001

Unión Europea, Reglamento (CE) 139 de 2004 del Consejo, sobre el control de concentraciones entre empresas, 024 Diario Oficial, 29 de enero de 2004. Disponible en: http://eur-lex.europa.eu/legal-content/ES/TXT/?uri=CELEX:32004R0139

Unión Europea, Reglamento (CE) 772 de 2004 de la Comisión, relativo a la aplicación del apartado 3 del artículo 81 del Tratado a determinadas categorías de acuerdos de transferencia de tecnología, 123 Diario Oficial de la Comunidad Europea, 27 de abril de 2004. Disponible en: http://eur-lex.europa.eu/legal-content/ES/ TXT/?uri=celex:32004R0772

Unión Europea, Reglamento (UE) 267 de 2010, relativo a la aplicación del artículo 101, apartado 3, del Tratado de Funcionamiento de la Unión Europea a determinadas categorías de acuerdos, decisiones y prácticas concertadas en el sector de los seguros, 83 Diario Oficial de la Unión Europea, 30 de marzo de 2010. Disponible en: http://eur-lex.europa.eu/legal-content/ES/TXT/?uri=CELEX:32010R0267

Unión Europea, Reglamento (UE) 330 de 2010 de la Comisión, relativo a la aplicación del artículo 101 apartado 3, del Tratado de Funcionamiento de la Unión Europea a determinadas categorías de acuerdos verticales y prácticas concertadas, 102 Diario Oficial de la Unión Europea, 23 de abril de 2010. Disponible en: http:// eur-lex.europa.eu/legal-content/ES/ALL/?uri=CELEX\%3A32010R0330

Unión Europea, Reglamento (UE) 461 de 2010, relativo a la aplicación del artículo 101, apartado 3, del Tratado de Funcionamiento de la Unión Europea a determinadas categorías de acuerdos verticales y prácticas concertadas en el sector de los vehículos de motor, 129 Diario Oficial de la Unión Europea, 28 de mayo de 2010. Disponible en: http://eur-lex.europa.eu/legal-content/ES/ TXT/?uri=celex:32010R0461

Unión Europea, Reglamento (UE) 1217 de 2010 de la Comisión, relativo a la aplicación del artículo 101 apartado 3, del Tratado de Funcionamiento de la Unión Europea a determinadas categorías de acuerdos de investigación y desarrollo, 335 Diario Oficial de la Unión Europea, 18 de diciembre de 2010. Disponible en: http://eur-lex. europa.eu/legal-content/ES/TXT/?uri=CELEX\%3A32010R1217

Unión Europea, Reglamento (UE) 1218 de 2010, relativo a la aplicación del artículo 101 apartado 3, del Tratado de Funcionamiento de la Unión Europea a determinadas categorías de acuerdos de especialización, 335 Diario Oficial de la Unión Europea, 18 de diciembre de 2010. Disponible en: http://eur-lex.europa.eu/LexUriServ/ LexUriServ.do?uri=OJ:L:2010:335:0043:0047:ES:PDF 


\section{Jurisprudencia y casuística}

Colombia, Consejo de Estado, Sala de lo Contencioso Administrativo, Sección 3, Subsección C, Proceso 54549, consejero ponente Jaime Orlando SantofimioGamboa, 4 de septiembre de 2015. Disponible en: Disponible en: http://sintesis. colombiacompra.gov.co/sites/default/files/sentencia/2015/CE $\% 20 \mathrm{SIII} \% 20 \mathrm{E} \% 20$ $54549 \% 20 \mathrm{DE} \% 202015 / \mathrm{CE} \% 20 \mathrm{SIII} \% 20 \mathrm{E} \% 2054549 \% 20 \mathrm{DE} \% 202015$ ORIGINAL. docx

Colombia, Corte Suprema de Justicia, Sala Plena, Sentencia C-415/1994, magistrado ponente Eduardo Cifuentes-Muñoz, 22 de septiembre de 1994.

Colombia, Superintendencia de Industria y Comercio, Resolución 1055 de 2009, Caso Intersystem, Buitrago Camargo y Vega Cruz, 19 de enero de 2009. Disponible en: http://www.sic.gov.co/recursos_user/documentos/normatividad/Publicaciones_ Despacho_3/sicdecisiones2/RESOLUCIONES_COMPETENCIA_ANOS/2009/ RESOLUCION_1055_DE_19_DE_ENERO_DE_2009_SANCION INTERSYSTEM.pdf

Comisión Europea, Decisión 84/380/CEE, Synthetic Fibres, comisionado Frans Andriessen, 4 de julio de 1984. Disponible en: http://eur-lex.europa.eu/legalcontent/FR/ALL/?uri=CELEX\%3A31984D0380

Comisión Europea, Decisión 85/77/CEE, Uniform Eurocheques, comisionado Leon Brittan, 10 de diciembre de 1984. Disponible en: http://eur-lex.europa.eu/legalcontent/EN/TXT/?uri=CELEX:31985D0077

Comisión Europea, Decisión 86/398/EEC, relating to a proceeding under Article 85 of the EEC Treaty (IV/31.149 - Polypropylene), April 23, 1986. Disponible en: http:// eur-lex.europa.eu/legal-content/EN/TXT/?uri=OJ:L:1986:230:TOC

Comisión Europea, Decisión 88/138/CEE, Eurofix Bauco contra Hilti, comisionado Peter Sutherland, 22 de diciembre de 1987. Disponible en: http://eur-lex.europa. eu/legal-content/ES/TXT/PDF/?uri=CELEX:31988D0138\&from=ES

Comisión Europea, Decisión 91/297, Soda-Ash-Solvay/ICI, comisionado Leon Brittan, 19 de diciembre de 1990. Disponible en: http://eur-lex.europa.eu/legal-content/ ES/TXT/?uri=CELEX\%3A31991D0297

Comisión Europea, Decisión 92/163/CEE, TetraPak II, comisionado presidente José Luis da Cruz-Vilaça, 24 de julio de 1991. Disponible en: http://eur-lex.europa. eu/legal-content/FR/TXT/?uri=CELEX\%3A31992D0163

Comisión Europea, Decisión 94/599/EC, relativa a un procedimiento de aplicación del artículo 85 del Tratado CE (IV/31.865, PVC), 27 de julio de 1994. Disponible en: http://eur-lex.europa.eu/legal-content/EN/TXT/?uri=CELEX\%3A31994D0599

Comisión Europea, Decisión 94/601/CE, relativa a un procedimiento de aplicación del artículo 85 del Tratado CE (IV/C/33.833 - cartoncillo - Cartonboard), 13 de julio de 1994. Disponible en: http://eur-lex.europa.eu/legal-content/ES/TXT/PDF/?u $\mathrm{ri}=$ CELEX:31994D0601\&from $=\mathrm{EN}$

Comisión Europea, Decisión 99/210/CE, relativa a un procedimiento con arreglo al artículo 85 del Tratado CE (asuntos IV/F-3/33.708 — British Sugar Plc, IV/F-3/33.709Tate \& Lyle Plc, IV/F-3/33.710 — Napier Brown \& Company Ltd y IV/F-3/33.711 — James Budgett Sugars Ltd), 13 de julio de 1994. Disponible en: http://eur-lex. 
europa.eu/legal-content/ES/TXT/PDF/?uri=CELEX:31999D0210\&from=EN

Comisión Europea, Decisión 1999/60/CE, relativa a un procedimiento con arreglo al artículo 85 del Tratado CE (IV/35.691/E-4: Cartel en el mercado de los tubos preaislados - Pre-Insulated Pipe Cartel), 21 de octubre de 1998. Disponible en: http://eur-lex.europa.eu/legal-content/ES/TXT/PDF/?uri=CELEX:31999D006 $0 \&$ from $=\mathrm{EN}$

Comisión Europea, Decisión 2001/354/CEE, Deutsche Post AG, comisionado Mario Monti, 20 de marzo de 2001. Disponible en: http://eur-lex.europa.eu/legalcontent/ES/TXT/?uri=CELEX\%3A32001D0354

Corte Europea de Justicia, Caso 58/64, Etablissements Consten SARL \& GrundigVerkaufs-GmbH v. Commission, 13 de julio de 1966. Disponible en: http://eur-lex. europa.eu/legal-content/ES/TXT/PDF/?uri=CELEX:61964CJ0056\&from=EN

Corte Europea de Justicia, Caso 32/65, República Italiana contra Comisión, 13 de julio de 1966. Disponible en: http://eur-lex.europa.eu/legal-content/ES/TXT/?print= true\&uri=CELEX\%3A61965CJ0032

Corte Europea de Justicia, Caso 56/65, Société Technique Minière, LTMv. Maschinenbau Ulm GmbH, MBU, 30 de junio de 1966. Disponible en: http://eur-lex.europa.eu/ legal-content/ES/TXT/?uri=CELEX\%3A61965CJ0056

Corte Europea de Justicia, Sala Primera, Asunto 48/69, Imperial Chemical Industries, ICI Ltd. v. Commission, Dyestuffs, magistrado Robert Lecourt, 14 de julio de 1972. Disponible en: http://eur-lex.europa.eu/legal-content/EN/ TXT/?uri=CELEX\%3A61969CJ0048

Corte Europea de Justicia, Sala Plena, Suiker Unie, Asunto 40/73, magistrado presidente Robert Lecourt, 16 de diciembre de 1975. Disponible en: http://curia.europa.eu/ juris/liste.jsf ?language $=$ en $\&$ num $=40 / 73$

Corte Europea de Justicia, Sala Plena, Asuntos 89, 104, 114, 116, 117, 125 al 129/85, presidente lord Alexander John Mackenzie-Stuart, 27 de septiembre de 1988. Disponible en: http://eur-lex.europa.eu/legal-content/ES/ALL/?uri=CELEX:61985CJ0089

Corte Europea de Justicia, Sala Quinta, Decisión C-62/86, Akzo Chemie BV v. Commission, juez René Joliet, 3 de julio de 1991. Disponible en: http://eur-lex. europa.eu/legal-content/EN/TXT/?uri=CELEX\%3A61986CJ0062

Corte Europea de Justicia, Case 213/86 R, Montedipe SpA v. Commission of the European Communities, September 24, 1986. Disponible en: http://curia.europa.eu/juris/ showPdf.jsf;jsessionid=9ea7d2dc30dbd33e849eec9d45fabaeb82522fda9725.e34 KaxiLc3qMb40Rch0SaxuLchf0?text $=\&$ docid $=94992 \&$ pageIndex $=0 \&$ doclang $=$ en $\&$ mode $=1$ st $\&$ dir $=\&$ occ $=$ first $\&$ part $=1 \&$ cid $=439178$

Corte Europea de Justicia, Sala Sexta, Rhone-Poulenc v. Commission, Caso T-1/89, 24 de octubre de 1991. Disponible en: http://curia.europa.eu/juris/showPdf.jsf?text $=\&$ docid $=104842 \&$ doclang $=\mathrm{EN}$

Corte Europea de Justicia, Sala Segunda, Dunlop Slazenger International Ltd $v$. Commission, Asunto T-43/92, 7 de julio de 1994. Disponible en: http://eur-lex. europa.eu/legal-content/ES/TXT/PDF/?uri=CELEX:61992TJ0043\&from=GA

Corte Europea de Justicia, Sala Sexta, Dunlop Slazenger International Ltd v. Commission, Asunto T-43/92, magistrado G. Federico Mancini, 8 de julio de 1999. Disponible 
en: http://eur-lex.europa.eu/legal-content/GA/TXT/?uri=CELEX:61992TJ0043

Corte Europea de Justicia, Sala Tercera Ampliada, Compagnie Maritime Belge Transports $S A$ v. Commission, Asunto T-28/93, magistrado ponente Cornelius Paulus Briët, 8 de octubre de 1996. Disponible en: http://eur-lex.europa.eu/legalcontent/EN/TXT/?uri=CELEX\%3A61993TJ0024

Corte Europea de Justicia, Sala Tercera Ampliada, Irish Sugar Plc v. Commission, Asunto T-228/97, magistrado ponente Koen Lenaerts, 7 de octubre de 1999. Disponible en: http://curia.europa.eu/juris/liste.jsf?language=en\&num=T-228/97

Corte Europea de Justicia, Sala Quinta Ampliada, France Télécom v. Commission, Asunto T-340/03, magistrado ponente Michail Vilaras, 30 de enero de 2007. Disponible en: http://curia.europa.eu/juris/liste.jsf?language $=$ en $\&$ jur $=C, T, F \& n u m=t-$ 340/03\&td=ALL

Corte Europea de Justicia, Limburgse Vinyl Maatschappij NV, Elf Atochem SA, BASF $A G$, Shell International Chemical Company Ltd, DSM NV, DSM Kunststoffen BV, Wacker-Chemie GmbH, Hoechst AG, Société Artésienne de Vinyle, Montedison $S p A$, Imperial Chemical Industries Plc, Hüls AG and Enichem SpA v. Commission, Caso T-305/94, 2 de abril de 1999. Disponible en: http://curia.europa.eu/juris/ liste.jsf?num $=\mathrm{T}-305 / 94 \&$ language $=\mathrm{en}$

Estados Unidos, Corte de Apelaciones del 2 Circuito, United States v. Aluminium Co. of America, Alcoa, 148 F.2d 416, $2^{\text {nd }}$ Circ. (March 12, 1945). Disponible en: http:// law.justia.com/cases/federal/appellate-courts/F2/148/416/1503668/

Estados Unidos, Corte de Apelaciones del 7 Circuito, In Re: High Fructose Corn Syrup Antitrust Litigation, 295 F.3d 651, 654, 7th Circ. (March 18, 2004). Disponible en: http://caselaw.findlaw.com/us-7th-circuit/1207079.html

Estados Unidos, Corte de Apelaciones del 8 Circuito, Blomkest Fertilizer, Inc. v. Potash Corp. of Saskatchewan, Inc., 203 F.3d 1028, 8th Circ. (February 17, 2000). Disponible en: https://h2o.law.harvard.edu/collages/35782

Estados Unidos, Corte de Apelaciones del 9 Circuito, Dedication \& Everlasting Love to Animals v. Humane Society, 50 F. 3d 710, 9th Circ. (March 20, 1995). Disponible en: http://caselaw.findlaw.com/us-9th-circuit/1051346.html

Estados Unidos, Corte de Apelaciones del 10 Circuito, United States v. AMR Corp., 335 F.3d 1109, 10th Cir. (July 3, 2003).

Estados Unidos, Corte de Apelaciones para el Circuito del Distrito de Columbia, National Petroleum Refiners Association v. Federal Trade Commission, FTC, 482 F.2d 672, 673-78, DC Circ. (1973). http://openjurist.org/482/f2d/672/nationalpetroleum-refiners-association-v-federal-trade-commission

Estados Unidos, Corte de Apelaciones para el Circuito del Distrito de Columbia, United States v. Microsoft Corporation, 253 F.3d 34 (D.C. Cir., June 28, 2001). Disponible en: http://law.justia.com/cases/federal/appellate-courts/F3/253/34/576095/

Estados Unidos, Suprema Corte, Addyston Pipe \& Steel Co. v. United States, 175 US 211 (December 4, 1899). Disponible en: https://supreme.justia.com/cases/federal/ us/175/211/case.html, https://www.law.cornell.edu/supremecourt/text/175/211

Estados Unidos, Suprema Corte, Arizona v. Maricopa County Medical Society, 457 US 332 (June 18, 1982). Disponible en: https://supreme.justia.com/cases/federal/ 
us/457/332/, https://www.law.cornell.edu/supremecourt/text/457/332

Estados Unidos, Suprema Corte, Broadcast Music v. Columbia Broadcasting System, $C B S, 441$ US 1 (April 17, 1979). Disponible en: https://supreme.justia.com/cases/ federal/us/441/1/case.html

Estados Unidos, Suprema Corte, Brooke Group Ltd. v. Brown \& Williamson Tobacco Corp., 509 US 209 (June 21, 1993). Disponible en: https://supreme.justia.com/ cases/federal/us/509/209/case.html

Estados Unidos, Suprema Corte, California v. ARC America Corp., 490 US 93, 104105 (April 18, 1989). Disponible en: https://supreme.justia.com/cases/federal/ us/490/93/

Estados Unidos, Suprema Corte, City of Columbia v. Omni Outdoor Advertising, 499 US 365, 372-73 (April 1, 1991). Disponible en: https://supreme.justia.com/cases/ federal/us/499/365/

Estados Unidos, Suprema Corte, Community Communications Co. v. City of Boulder, 455 US 40, 50-54 (January 13, 1982). Disponible en: http://caselaw.findlaw.com/ussupreme-court/455/40.html, https://supreme.justia.com/cases/federal/us/455/40/

Estados Unidos, Suprema Corte, Continental T.V. Inc. v. GTE Sylvania Inc., 433 US 36 (June 23, 1977). Disponible en: https://supreme.justia.com/cases/federal/ us/433/36/case.html

Estados Unidos, Suprema Corte, Credit Suisse Securities v. Billing, 551 US 264, 275 (June 18, 2007). Disponible en: https://supreme.justia.com/cases/federal/us/551/264/

Estados Unidos, Suprema Corte, Eastman Kodak Co. v. Image Technical Servs., Inc., 504 US 451 (June 8, 1992). Disponible en: https://supreme.justia.com/cases/federal/ us/504/451/case.html

Estados Unidos, Suprema Corte, Fisher v. City of Berkeley, 475 US 260 (February 26, 1986). Disponible en: https://supreme.justia.com/cases/federal/us/475/260/

Estados Unidos, Suprema Corte, Flood v. Kuhn, 407 US 258 (June 19, 1972). Disponible en: https://supreme.justia.com/cases/federal/us/407/258/case.html

Estados Unidos, Suprema Corte, Federal Trade Commission, FTC v. Motion Picture Advertising Svc. Co., Inc., 344 US 392 (February 2, 1953). Disponible en: https:// supreme.justia.com/cases/federal/us/344/392/

Estados Unidos, Suprema Corte, Gordon v. New York Stock Exchange, Inc., 422 US 659 (June 26, 1975). Disponible en: https://supreme.justia.com/cases/federal/ us/422/659/

Estados Unidos, Suprema Corte, Group Life \& Health Ins. Co. v Royal Drug Co., 440 US 205, 231 (February 27, 1979). Disponible en: https://supreme.justia.com/ cases/federal/us/440/205/

Estados Unidos, Suprema Corte, Hoover v. Ronwin, 466 US 558, 567-69 (May 14, 1984). Disponible en: https://supreme.justia.com/cases/federal/us/466/558/case.html

Estados Unidos, Suprema Corte, Illinois Tool Works Inc. v. Independent Ink, Inc., 547 US 28 (March 1, 2006). Disponible en: https://supreme.justia.com/cases/federal/ us/547/28/opinion.html 
Estados Unidos, Suprema Corte, Jefferson Parish Hospital District No. 2 v. Hyde, 466 US 2 (March 27, 1984). Disponible en: https://supreme.justia.com/cases/federal/ us/466/2/

Estados Unidos, Suprema Corte, Leegin Creative Leathers Products, Inc. v. PSKS, Inc., 127 S Ct 2705 (June 28, 2007). Disponible en: https://www.law.cornell.edu/supct/ html/06-480.ZO.html

Estados Unidos, Suprema Corte, Maryland \& Virginia Milk Producers Association v. United States, 362 US 458 (May 2, 1960). Disponible en: https://www.law.cornell. edu/supremecourt/text/362/458

Estados Unidos, Suprema Corte, McLain v. Real Estate Board of New Orleans, 444 US 232 (January 8, 1980). Disponible en: https://supreme.justia.com/cases/federal/ us/444/232/case.html

Estados Unidos, Suprema Corte, National Collegiate Athletic Association, NCAA v. University of Oklahoma Board of Regents, 468 US 85, 109 (June 2, 1984). Disponible en: https://supreme.justia.com/cases/federal/us/468/85/case.html

Estados Unidos, Suprema Corte, National Gerimedical Hospital \& Gerontology Center v. Blue Cross of Kansas City, 452 US 378, 389 (June 15, 1981). Disponible en: https://supreme.justia.com/cases/federal/us/452/378/

Estados Unidos, Suprema Corte, Northern Securities Co. v. United States, 193 US 197 (March 14, 1904). Disponible en: https://www.law.cornell.edu/supremecourt/ text/193/197

Estados Unidos, Suprema Corte, Palmer v. BRG of Georgia, Inc., 498 US 46 (1990). Disponible en: https://supreme.justia.com/cases/federal/us/498/46/

Estados Unidos, Suprema Corte, Silver v. New York Stock Exchange, NYSE, 373 US 341, 357 (May 20, 1963). Disponible en: https://supreme.justia.com/cases/federal/ us/373/341/case.html

Estados Unidos, Suprema Corte, Standard Fashion Co. v. Magrane-Houston Co., 258 US 346 (April 10, 1922). Disponible en: https://supreme.justia.com/cases/federal/ us/258/346/case.html

Estados Unidos, Suprema Corte, Standard Oil Co. v. United States, 337 US 293 (June 13, 1949). Disponible en: https://supreme.justia.com/cases/federal/us/337/293/ case.html

Estados Unidos, Suprema Corte, State Oil v. Khan, 522 US 3 (1997). Disponible en: https://supreme.justia.com/cases/federal/us/522/3/case.html

Estados Unidos, Suprema Corte, Summit Health v. Pinhas, 500 US 322 (May 28, 1991). Disponible en: https://supreme.justia.com/cases/federal/us/500/322/case.html

Estados Unidos, Suprema Corte, Tampa Electric Co. v. Nashville Coal Co., 365 US 320 (February 27, 1961). Disponible en: https://supreme.justia.com/cases/federal/ us/365/320/case.html

Estados Unidos, Suprema Corte, Texaco Inc. v. Dagher, 547 US 1 (2006). Disponible en: https://supreme.justia.com/cases/federal/us/547/1/

Estados Unidos, Suprema Corte, Theatre Enterprises Inc. v. Paramount Film Distributing Corp., 346 US 537 (1954). Disponible en: https://supreme.justia.com/cases/federal/ 
us/346/537/case.html

Estados Unidos, Suprema Corte, United States v. E. C. Knight Co., 156 US 1 (January 21, 1895). Disponible en: https://supreme.justia.com/cases/federal/us/156/1/case.html

Estados Unidos, Suprema Corte, United States v. E. I. du Pont de Nemours \& Co., caso celofán, 351 US 377 (June 11, 1956). Disponible en: https://supreme.justia.com/ cases/federal/us/351/377/

Estados Unidos, Suprema Corte, United States v. Griffith, 334 US 100 (May 3, 1948). Disponible en: https://supreme.justia.com/cases/federal/us/334/100/

Estados Unidos, Suprema Corte, United States v. Socony-Vacuum Oil Co., 310 US 150 (May 6, 1940). Disponible en: https://supreme.justia.com/cases/federal/us/310/150/ case.html

Estados Unidos, Suprema Corte, United States v. Trenton Potteries Co., 273 US 392 (February 21, 1927). Disponible en: https://supreme.justia.com/cases/federal/ us/273/392/case.html

Tribunal de Justicia de las Comunidades Europeas, Sala Plena, Microsoft v. Comisión, Asunto T-201/04, magistrado presidente Bo Vesterdorf, 17 de septiembre de 2007. Disponible en: http://curia.europa.eu/juris/liste.jsf?language=es\&num=T-201/04\# 
